\title{
Anatomy of Subcortical Structures Predicts Age- Related Differences in Skill Acquisition
}

Citation for published version (APA):

Chalavi, S., Adab, H. Z., Pauwels, L., Beets, I. A. M., van Ruitenbeek, P., Boisgontier, M. P., Monteiro, T. S., Maes, C., Sunaert, S., \& Swinnen, S. P. (2018). Anatomy of Subcortical Structures Predicts AgeRelated Differences in Skill Acquisition. Cerebral Cortex, 28(2), 459-473.

https://doi.org/10.1093/cercor/bhw382

Document status and date:

Published: 01/02/2018

DOI:

10.1093/cercor/bhw382

Document Version:

Publisher's PDF, also known as Version of record

Document license:

Taverne

Please check the document version of this publication:

- A submitted manuscript is the version of the article upon submission and before peer-review. There can be important differences between the submitted version and the official published version of record.

People interested in the research are advised to contact the author for the final version of the publication, or visit the DOI to the publisher's website.

- The final author version and the galley proof are versions of the publication after peer review.

- The final published version features the final layout of the paper including the volume, issue and page numbers.

Link to publication

\footnotetext{
General rights rights.

- You may freely distribute the URL identifying the publication in the public portal. please follow below link for the End User Agreement:

www.umlib.nl/taverne-license

Take down policy

If you believe that this document breaches copyright please contact us at:

repository@maastrichtuniversity.nl

providing details and we will investigate your claim.
}

Copyright and moral rights for the publications made accessible in the public portal are retained by the authors and/or other copyright owners and it is a condition of accessing publications that users recognise and abide by the legal requirements associated with these

- Users may download and print one copy of any publication from the public portal for the purpose of private study or research.

- You may not further distribute the material or use it for any profit-making activity or commercial gain

If the publication is distributed under the terms of Article $25 \mathrm{fa}$ of the Dutch Copyright Act, indicated by the "Taverne" license above, 


\title{
Anatomy of Subcortical Structures Predicts Age-Related Differences in Skill Acquisition
}

\author{
Sima Chalavi ${ }^{1, \dagger}$, Hamed Zivari Adab ${ }^{1, \dagger}$, Lisa Pauwels ${ }^{1}$, Iseult A. M. Beets ${ }^{1,2}$, \\ Peter van Ruitenbeek ${ }^{1,3}$, Matthieu P. Boisgontier ${ }^{1}$, Thiago Santos Monteiro ${ }^{1}$, \\ Celine Maes ${ }^{1}$, Stefan Sunaert ${ }^{4}$ and Stephan P. Swinnen ${ }^{1,5}$
}

${ }^{1}$ Department of Kinesiology, Biomedical Sciences Group, Movement Control and Neuroplasticity Research Center, KU Leuven, 3001 Leuven, Belgium, ${ }^{2}$ BrainCTR, Lilid bvba, 3290 Diest, Belgium, ${ }^{3}$ Faculty of Psychology and Neuroscience, Department of Clinical Psychological Science, Maastricht University, 6200 MD Maastricht, The Netherlands, ${ }^{4}$ Department of Imaging and Pathology, Biomedical Sciences Group, Translational MRI Unit, KU Leuven, 3000 Leuven, Belgium and ${ }^{5}$ Leuven Research Institute for Neuroscience \& Disease (LIND), KU Leuven, 3000 Leuven, Belgium

Address correspondence to Stephan P. Swinnen, Tervuursevest 101, B-3001 Heverlee, Belgium. Email: Stephan.Swinnen@kuleuven.be

${ }^{\dagger}$ These authors contributed equally to this study.

\begin{abstract}
Skill acquisition capabilities vary substantially from one individual to another. Volumetric brain studies have demonstrated that global volume of several subcortical structures predicts variations in learning outcome in young adults (YA) and older adults (OA). In this study, for the first time, we utilized shape analysis, which offers a more sensitive detection of subregional brain anatomical deformations, to investigate whether subregional anatomy of subcortical structures is associated with traininginduced performance improvement on a bimanual task in YA and OA, and whether this association is age-dependent. Compared with YA, OA showed poorer performance, greater performance improvement, and smaller global volume and compressed subregional shape in subcortical structures. In OA, global volume of the right nucleus accumbens and subregional shape of the right thalamus, caudate, putamen and nucleus accumbens were positively correlated with acquisition of difficult (non-preferred) but not easy (preferred) task conditions. In YA, global volume and subregional shape of the right hippocampus were negatively correlated with performance improvement in both the easy and difficult conditions. We argue that pre-existing neuroanatomical measures of subcortical structures involved in motor learning differentially predict skill acquisition potential in YA and OA.
\end{abstract}

Key words: bimanual skill acquisition, global volume, motor learning, subcortical structures, subregional shape

\section{Introduction}

Aging has been associated with declines in several cognitive and sensorimotor abilities (Brosseau et al. 2007; Cai et al. 2014). These declines can limit the ability of older adults (OA) to independently perform their daily life activities. Age-related decline in motor skill acquisition is an example of such cognitive and sensorimotor deficits (Swinnen et al. 1998; Seidler et al. 2010).
Converging evidence suggests that, on average, OA learn motor skills at a slower rate and, despite extended task practice, may not attain the same performance level as their younger counterparts (Fozard et al. 1994; Desrosiers et al. 1999; Smith et al. 2005; King et al. 2013). Several factors may lead to these age-related deficits including changes in the biochemistry and neuroanatomy of the central nervous system and/or alterations in the peripheral 
nervous system. However, in both young adults (YA) and OA, motor skill acquisition may vary substantially from one individual to another (Unsworth and Engle 2005; Tubau et al. 2007; Voelcker-Rehage 2008). The variability in skill acquisition potential may, at least partially, stem from these inter-individual variations in brain neuroanatomy and biochemistry.

Advances in neuroimaging techniques have offered a unique window into exploring brain structure and function. Functional neuroimaging studies have implicated the cerebellum and several cortical regions in motor learning, including the primary motor, premotor, prefrontal and parietal cortices (Jueptner et al. 1997b; Toni et al. 1998; Doyon et al. 2003; Debaere et al. 2004a; Puttemans et al. 2005; Rémy et al. 2008). In addition, the basal ganglia are also considered crucial in motor learning. The basal ganglia are a group of nuclei composed of the caudate, putamen, nucleus accumbens, pallidum, substantia nigra, subthalamic nucleus, and olfactory tubercle. The striatal structures (caudate, putamen, and nucleus accumbens) receive cortical inputs from the associative, premotor, and sensorimotor cortices and have been implicated in the learning and execution of motor sequence memory and bimanual visuomotor tracking tasks (Graybiel 1995; Salmon and Butters 1995; Hikosaka et al. 1999; Debaere et al. 2004a; Doyon and Benali 2005; Lehéricy et al. 2005; Halsband and Lange 2006; Haruno and Kawato 2006). It has been shown that the rostro-dorsal (associative) portions of the striatum are involved in the early stages of motor learning and the more caudo-ventral (sensorimotor) portions of the striatum are involved at the later stages of learning (Jueptner et al. 1997a; Toni et al. 1998; Doyon et al. 2002; Lehéricy et al. 2005). The nucleus accumbens, which is part of the limbic circuitry related to reward learning and motivation (Belin and Everitt 2008; Graybiel 2008; De Martino et al. 2009), has also shown to be involved in spatial learning and memory, selection of flexible behavior, and translation of motivation into motor actions (Mogenson et al. 1980; Rinaldi et al. 2012; Floresco 2015). Besides the basal ganglia, the hippocampus has also been implicated in the acquisition and consolidation of motor sequence memory (Albouy et al. 2008, 2013; Rémy et al. 2008).

So far, only a limited number of studies have investigated whether individual variations in anatomical measures of gray matter (GM) or white matter (WM) can explain variations in motor learning performance. Using diffusion tensor imaging, 3 studies have reported that variations in the WM microstructural organization of the fiber tracts of the genu (connecting bilateral prefrontal cortices) (Sisti et al. 2012) and body (connecting bilateral supplementary motor area and caudal cingulate motor area) (Johansen-Berg et al. 2007) of the corpus callosum as well as WM microstructural organization of some cerebellar fiber tracts (connecting the cerebellar cortex with motor and premotor cortex) (Della-Maggiore et al. 2009) account for motor skill acquisition variability in YA. Other studies utilized anatomical measures of GM to predict skill acquisition. Erickson et al. (2010) tested video game skill acquisition in YA and reported that global volume of both the dorsal and ventral striatum could predict early skill acquisition rates. Tomassini et al. (2011) used a multimodal approach by combining findings from functional, diffusion-weighted, and structural magnetic resonance imaging (MRI) data in YA. They reported that variations in motor performance improvement on a unimanual visuomotor tracking task correlated with WM microstructural organization in the premotor cortex and cerebellum and with GM density in the cerebellum. Kennedy and Raz (2005) used a unimanual mirror drawing task and investigated whether age, gender, and regional volume could predict training outcome in both YA and OA. They found that larger lateral prefrontal cortex was positively associated with better learning outcome, particularly in older participants. Moreover, they reported that larger caudate was associated with more improvement at a later phase of learning among men and at an earlier phase of learning among women.

Except for Kennedy and Raz (2005), all the aforementioned studies investigating the predictive value of brain anatomy in learning outcome only included YA participants. Neuroimaging studies have reported age-related GM atrophy in numerous brain regions, including those subcortical structures involved in motor performance and skill acquisition (Raz et al. 2005; Cherubini et al. 2009; Fjell et al. 2013; Serbruyns et al. 2015). This age-related subcortical atrophy could, at least partially, explain skill acquisition decline in elderly. However, it still remains elusive whether variations in the anatomical measures of medial subcortical GM structures show a differential association with learning outcomes in YA and OA.

Furthermore, all the above mentioned studies on GM structure either performed volumetric analyses on global volume of the subcortical structures or used a voxel-based morphometry approach, both of which have shown lower sensitivity than shape analysis in detecting subtle anatomical changes (Patenaude et al. 2011; Menke et al. 2014). Indeed, exploring subregional structural deformations using shape analysis techniques can offer a more sensitive approach in detecting subtle age-related regional alterations and brain-behavior effects (Serbruyns et al. 2015). For example, several structural MRI studies have reported that while volumetric analysis, using global volume of the subcortical structure, failed to detect effects of interest, shape analysis was successful. This difference could/may be explained by effects localized in specific subregions of a structure, which are associated with specific functions (Posener et al. 2003; Ballmaier et al. 2008; Joseph et al. 2014; Serbruyns et al. 2015), or by compressions and expansions of different subregions, canceling each other's effect (Qiu et al. 2009a; Sandman et al. 2014). Apart from the claimed higher sensitivity, the shape analysis approach can also help in better understanding the functional relevance of the morphological changes. Specifically, individual subregions within subcortical structures have distinct connections to areas of the cortical territory or to the other subcortical structures and thus contribute to distinctive functions. Therefore, identifying subregional morphological changes using shape analysis can improve our understanding of age- or pathology-related alterations in specific functions. For example, a recent aging study reported that only compression in the ventro-lateral subregion of the bilateral thalamus, which specifically subserves connectivity with the premotor, primary motor and somatosensory cortical areas, mediated the relation between aging and performance decline in a clinical bimanual task (Serbruyns et al. 2015). In another study, Qiu and colleagues (2009a), who investigated shape of the basal ganglia structures in children with attention deficit hyperactivity disorder (ADHD), reported patterns of compression in the head and body of the caudate, anterior putamen and pallidum, and ventral putamen, as well as patterns of subregional expansions in the posterior putamen, in boys with ADHD as compared with typically developing boys. Based on the connectivity patterns of these subregions, they concluded that brain structural deformations in ADHD involve multiple frontalsubcortical control loops, including circuits with premotor, oculomotor, and prefrontal cortices. Altogether, shape analysis is not only a sensitive technique to detect localized effects, but can also shed light onto the functional relevance of the observed structural changes (Qiu et al. 2008; Coscia et al. 2009; Zarei et al. 2010).

In the current study, YA and OA underwent anatomical imaging and were subsequently trained on a bimanual visuomotor task. 
We investigated age differences in global volume and subregional shape of brain medial subcortical GM structures, that is, thalamus, putamen, pallidum, nucleus accumbens, caudate, and hippocampus (Debaere et al. 2003, 2004a; Puttemans et al. 2005; Kraft et al. 2007; Rémy et al. 2008). While these subcortical structures are involved in various cognitive, motor, and limbic functions, we explored whether motor skill learning is specifically correlated with the anatomical measures of the subcortical structures involved in motor processing and skill acquisition and whether this relationship varies with age. For this purpose, we examined associations between training-induced performance improvement and global volume and subregional shape measures within and across age groups.

Six hypotheses were proposed. 1) At the behavioral level, we expected that OA, as compared with YA, would show poorer motor performance level and lower skill improvement. 2) With regard to the brain measures, we expected to find a smaller global volume as well as a compressed subregional shape in all the subcortical structures in OA. 3) Furthermore, within each age group, we expected to observe associations between morphological measures of subcortical structures and performance improvement, particularly in the basal ganglia nuclei as inferred from functional magnetic resonance imaging (fMRI) studies, showing an involvement of these regions in motor learning (Graybiel 1995; Salmon and Butters 1995; Hikosaka et al. 1999; Debaere et al. 2004a; Doyon and Benali 2005; Lehéricy et al. 2005; Halsband and Lange 2006; Haruno and Kawato 2006). 4) In view of the anticipated subcortical differences between OA and YA (hypothesis 2) and their role in learning, we expected the positive associations between brain neuroanatomical metrics and motor skill learning measures to be stronger within the OA than YA group (i.e., an age-dependent effect). Particularly, as compared with YA, we hypothesized that OA with greater subcortical volumes and lower inward deformation would show greater improvement in performance, specifically for those structures that have been associated with learning, that is, the thalamus and striatal structures (Debaere et al. 2004a; Doyon and Benali 2005). 5) Additionally, we expected that subcortical structures that are highly involved in motor learning (i.e., the thalamus and striatum) would show stronger associations with performance improvement in the difficult as compared with easy task variants, reflecting taskspecificity of the positive associations. 6) Finally, as shape analysis has been reported to be more sensitive in detecting subtle effects than the global volumetric measures, we expected to find more significant group differences and brain-behavioral correlations using the shape measures.

\section{Materials and Methods}

\section{Participants}

Twenty-five YA (age: $21.08 \pm 2.34$ years; 14 females) and $23 \mathrm{OA}$ (age: $68.65 \pm 5.57$ years; 12 females) right-handed (Oldfield 1971) volunteers participated in the study. The groups did not differ significantly with respect to gender $\left(\mathrm{Chi}^{2}=0.71, \mathrm{P}=0.79\right)$. All participants had normal or corrected-to-normal vision. They provided their written informed consent and all procedures were performed according to guidelines established by the ethics committee for biomedical research at the KU Leuven, and in accordance with the WMA International Code of Medical Ethics.

\section{Task}

We used a bimanual tracking task in which 2 dials controlled the direction and speed of a cursor on a computer screen: the left dial controlled displacement along the $y$-axis and the right dial along the $x$-axis (Fig. 1a; for details see Sisti et al. 2012). Participants were instructed to track a white target dot moving along a line by rotating both dials simultaneously (Fig. 1b). During the 9-s trial, the target dot moved over the line at a constant speed from start (center of the screen) to end. The goal was to track the white target dot movement as closely as possible. The inter-trial interval was $3 \mathrm{~s}$. Four coordination patterns imposed by the line direction were tested: both hands rotating inwards, outwards, clockwise, or counter-clockwise. Each pattern was performed with 5 distinct inter-hand frequency ratios, comprising 1:1, 1:2, 1:3, 2:1, and 3:1 (left hand:right hand) (Fig. 1c).

\section{Procedure}

This study was part of a larger project investigating the neural mechanisms underlying bimanual task performance using different modalities including fMRI and structural MRI (Beets et al. 2015). The protocol consisted of 3 phases: a pre-test scanning phase, a training phase, and a post-test scanning phase. The training phase included 5 practice sessions of $1.5 \mathrm{~h}$ each, distributed over 2 weeks. Participants were tested in the scanner for $1 \mathrm{~h}$ at the beginning (Pre-test) and at the end (Post-test) of this training period. During the 5 training sessions, which took place outside the scanner, participants were seated in front of a computer screen (distance $\sim 0.5 \mathrm{~m}$ ), with vision of the hands being occluded (Fig. 1b). On each of the 5 training days, 10 blocks of 20 randomized trials were performed with and without augmented visual feedback. During the visual feedback trials, participant's actual performance was displayed online on the screen with a red cursor on top of a white target dot showing required performance. For the trials without augmented

(a)

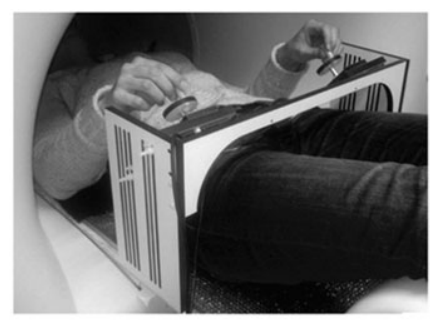

(b)

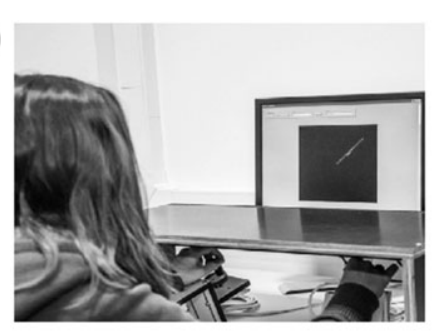

(c)

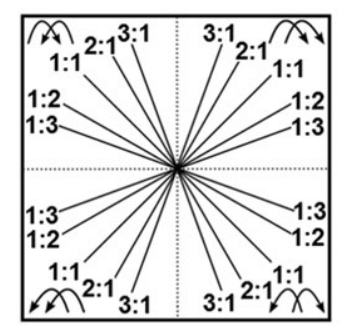

Figure 1. Experimental setup (a) in the scanner at Pre- and Post-test and $(b)$ on the training days. (c) All possible bimanual directional combinations $(n=4)$ and frequency ratios $(n=5)$. 
online feedback, the participant's performance cursor was displayed in red on top of the target dot but only for $1 \mathrm{~s}$ after each trial had ended to reduce dependency on online visual feedback. On the Pre-test and Post-test days, which took place in the MRI scanner, we used a similar device while participants laid supine (Fig. 1a) with forearms resting on pillows. Visual stimuli were projected by an LCD projector (Barco 6300, $1280 \times$ 1024 pixels) onto a double mirror placed in front of the participant's eyes. A non-ferromagnetic apparatus with 2 dials (diameter $=5 \mathrm{~cm}$ ) was placed over the participant's thighs. Each MRI session consisted of 96 active trials divided into 6 runs with an inter-run interval of approximately $3 \mathrm{~min}$. Half of the trials presented at Pre-test and Post-test were performed with online visual feedback. That is, concurrent visual feedback was provided by means of a red cursor displaying the actual tracking trajectory based on the contribution of both limbs. The other half of the trials was performed without any online visual feedback. In this study, we collapsed the performance outcomes of the trials with and without visual feedback.

\section{Kinematic Data Analyses}

Data were recorded and analyzed with the Labview software (version 8.5, National Instruments, Austin, TX, USA). The $\mathrm{x}$ and $\mathrm{y}$ positions of the target dot to be tracked and the participants' actual cursor were sampled at $100 \mathrm{~Hz}$. Offline analysis was carried out using Matlab R2011b. For each trial, the Euclidian distance between the target and the cursor position at each point in time was measured and subsequently averaged over the whole trial duration. This dependent measure will from now on be called "trial error score". The trial error score was used as an indicator of accuracy with lower values reflecting better performance. Outlier trials $(z>3)$ were discarded from the analysis.

First, within each day and for each inter-hand frequency ratio, subjects' trial error scores were averaged across the 4 quadrants. For both YA and OA, we observed that trials with different inter-hand frequency ratios (i.e., 1:2, 1:3, 2:1, 3:1) provided a greater challenge during learning than the trials with similar (preferred) inter-hand frequency ratio (i.e., 1:1), as anticipated (see Fig. $3 a$ and Behavioral Results). Moreover, no significant differences were observed among the conditions with different inter-hand frequency ratios (see Results). Because of the latter finding and to reduce the dimensionality of our measurements, we further averaged the trial error scores of the trials with different inter-hand frequency ratios, resulting in a single error score, referred to as the average trial error score during "non-iso task conditions". Later, we compared the statistical results of this collapsed average trial error score to the average trial error score of trials with similar inter-hand frequency ratio, from now on being referred to as the average trial error score during the "iso task condition". Furthermore, for each participant, performance improvements (in both non-iso and iso task conditions) were calculated by subtracting the average trial error score of the Post-test from that of the Pre-test (indicated as Pre-to-Post performance improvement).

\section{Image Acquisition}

A Siemens 3-T Magnetom Trio MRI scanner (Siemens, Erlangen, Germany) with a 12-channel head coil was used for acquisition of high-resolution T1-weighted structural images [MPRAGE; repetition time $(\mathrm{TR}) / \mathrm{echo}$ time $(\mathrm{TE})=2300 / 2.98 \mathrm{~ms}, 1 \times 1 \times$ $1.1 \mathrm{~mm}^{3}$ voxels, field of view $=240 \times 256 \mathrm{~mm}^{2}, 160$ sagittal slices, flip angle $=9^{\circ}$.

\section{Global Volumetric Analysis}

First, all the anatomical images were manually checked for the presence of anatomical abnormalities or MR artifacts. Automatic segmentation of the subcortical structures (bilateral thalamus, caudate, putamen, pallidum, hippocampus, and nucleus accumbens) from each participant's anatomical image was conducted using FMRIB's Integrated Registration Segmentation Toolkit (FSL FIRST; http://fsl.fmrib.ox.ac.uk/fsl/fslwiki/FIRST) (Fig. 2). Global volume of each subcortical structure was obtained from the outputs of the FSL FIRST segmentation and was imported into the Statistical Package for the Social Sciences (SPSS, version 22.0; IBM, Armonk, NY, USA). Furthermore, total intracranial volume (TIV) was obtained using FreeSurfer (http://freesurfer.net/) and was used as a covariate in the subsequent analyses to correct for variations in brain size.

\section{Subregional Shape Analysis}

FSL FIRST uses a deformable mesh model, constructed from a training set of 336 manually segmented anatomical images, to create a surface mesh for each subcortical structure. These deformable meshes consist of sets of vertices connected by edges and are topologically equivalent to a tessellated sphere. The number of vertices for each structure is fixed so that corresponding vertices can be compared across individuals and between groups. Vertex-wise statistics were carried out using FSL version 5.0. First, all surfaces were aligned to the FIRST model space (MNI152). Pose (rotation and translation) was removed by minimizing the sum-of-squares difference between corresponding vertices of a participants' surface and the target surface. A general linear model approach, as implemented in FSL, with Threshold-Free Cluster Enhancement correction for multiple comparisons (Smith and Nichols 2009) was employed to perform 2-sample t-tests for group comparisons as well as regression analyses between localized shape and behavior. Results were rendered on the shape surface, providing a map of the subregions where the structure was significantly different between groups, and/or correlated with behavior.

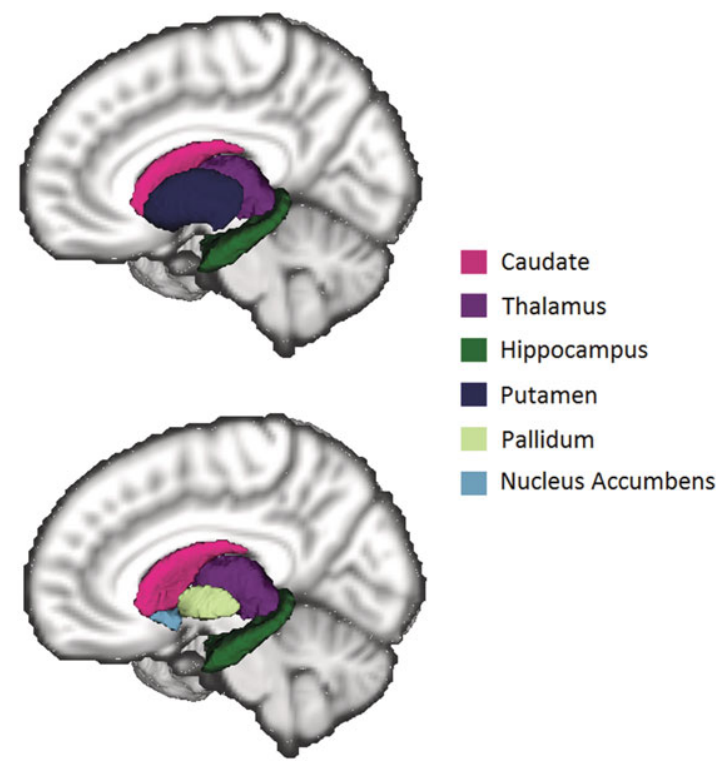

Figure 2. Subcortical structures segmented using FIRST. In the bottom figure, the putamen has been removed to better illustrate the pallidum and nucleus accumbens. 
We used the Oxford Thalamic Connectivity Probability (Johansen-Berg et al. 2005) and the Oxford-Imanova Striatal Connectivity (Tziortzi et al. 2014) atlases thresholded at $25 \%$ of the maximum connectivity count, to visualize the cortical connectivity profile of the subcortical structures.

\section{Statistical Analyses}

Statistical analyses were performed using SPSS. First, we investigated whether there were differences between the age groups in the error scores of all the trials (i.e., 1:1, 3:1, 2:1, 1:2, and 1:3) at Pre-test and Post-test (hypothesis 1). To do so, a $2 \times 2 \times 5$ (Age Group $\times$ Pre- or Post-test $\times$ Inter-Hand Frequency ratio) analysis of variance (ANOVA) with repeated measures on the latter 2 factors was conducted. Results of this analysis indicated a distinction between the trials with non-iso and those with iso inter-hand frequency ratio (see "Behavioral performance" section). Therefore, to assess training-induced changes in motor performance across the age groups and across all 7 days in these 2 different types of task condition (i.e., iso and non-iso), a $2 \times 2 \times 7$ (age group $\times$ task difficulty condition $\times$ day) repeated measures ANOVA was conducted.

Regarding the anatomical measures and to test hypothesis 2, global volume was compared across age groups using univariate analyses of co-variance (ANCOVAs), with TIV and gender as covariates and age group as a between-subject factor. Correction for multiple comparisons was applied using false discovery rate (FDR) correction and an alpha level of 0.05 was chosen. Moreover, patterns of subregional group differences in subcortical structures were explored using shape analysis.

In order to test hypothesis 3 and investigate whether variations in the global volume or subregional shape of the regions of interest can explain training-induced performance improvement, a series of partial correlations were performed between Pre-to-Post performance improvement scores and global volume and subregional shape of the subcortical structures within each age group. The latter statistics were controlled for initial performance at Pre-test, TIV, and gender.

Additionally, to investigate whether global volume of any subcortical structure is differentially related with the Pre-toPost performance improvement measure across the age groups (hypothesis 4), a series of multiple regression analyses with the "enter" method were performed using the Pre-to-Post performance improvement score as main dependent variable and the global volume of the subcortical structures as independent variable. In the latter analyses, initial performance at the Pretest, TIV, and gender were entered as extra covariates. Additionally, interaction between age group and global volume of the subcortical structures was also entered as an independent variable. The interaction effect on the subregional shape was also assessed using shape analysis. For the interaction analyses an alpha level of 0.05 (uncorrected) was used.

Furthermore, we hypothesized that those subcortical structures that are highly involved in motor learning (i.e., the thalamus and striatum) would generally show stronger positive associations with performance improvement in the difficult, than the easy, task variants (hypothesis 5). To do so, for each of the correlation and regression analyses, the coefficients were calculated for the easy (i.e., iso task condition) and difficult (i.e., non-iso task condition) task variants and were statistically compared. Finally, we investigated whether shape analysis could detect more subtle effects than the volumetric approach (hypothesis 6), as suggested by previous literature (Patenaude et al. 2011; Menke et al. 2014; Serbruyns et al. 2015).

\section{Results}

\section{Behavioral Performance}

To study hypothesis 1 , a repeated measures ANOVA tested for differences in trial error scores of all the trials (1:1, 3:1, 2:1, 1:2 and 1:3) across 2 testing days (Pre-test vs. Post-test) and across age groups (YA vs. OA). Results revealed a significant main effect of age group $[F(1,44)=56.164, P<0.001]$, indicating that average performance was better in YA as compared with OA, across Pre-test and Post-test sessions. A significant main effect of testing day $[F(1,44)=164.97, P<0.001]$ was also found, indicating that performance was better at Post-test as compared with Pre-test. Finally, a significant main effect of inter-hand frequency ratio $[F(4,41)=63.04, P<0.001]$ was observed (Fig. 3a), whereby trial error score was higher in all the trials with different inter-hand frequency ratio (i.e., 3:1, 2:1, 1:2, 1:3, all $P<$ 0.001 ) than in the trials with similar inter-hand frequency ratio (i.e., 1:1). There was a significant interaction effect of testing day $\times$ age group $[F(1,44)=24.97, P<0.001]$, indicating that performance improvement from Pre-test to Post-test was larger in OA than YA. Additionally, there was an interaction effect of age group $\times$ inter-hand frequency ratio $[F(4,41)=5.55, P=0.001]$,

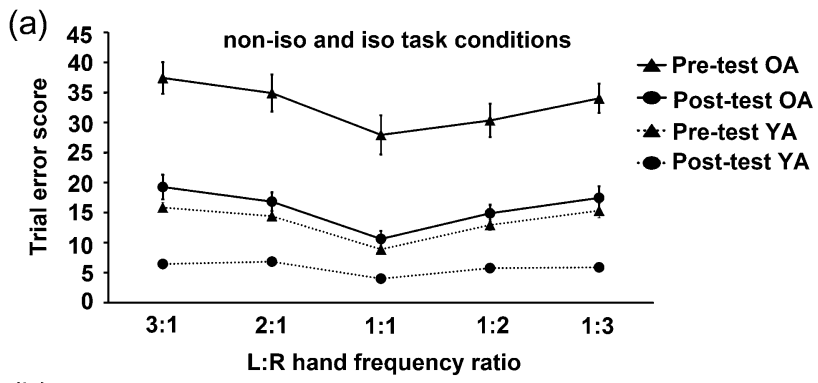

(b)

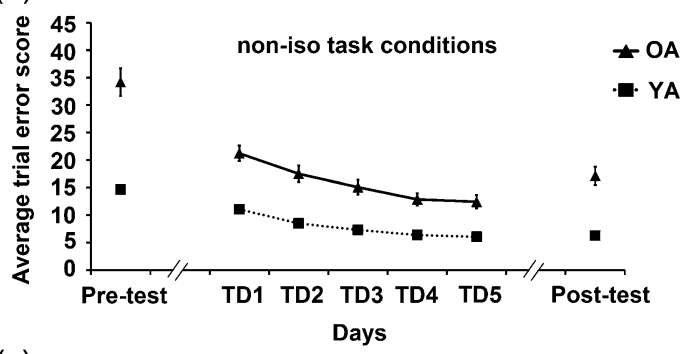

(c)

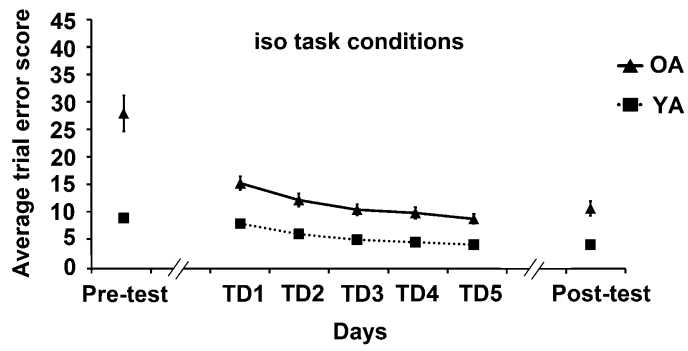

Figure 3. Error scores across testing days. (a) In both YA and OA, trial errors were higher in the non-iso task conditions than in the iso task conditions. Furthermore, OA consistently showed higher errors than YA. Panels (b) and (c) represent average trial error scores in the non-iso and iso task conditions, respectively. For both task conditions, performance of both YA and OA improved throughout the training days. Moreover, although OA consistently showed higher error scores, their performance improvement was greater than YA. L:R, left:right; TD, training day; iso, trials with similar inter-hand frequency ratio (i.e., 1:1); non-iso, trials with different inter-hand frequency ratio (i.e., 1:2, $2: 1,1: 3$, and $3: 1)$ 
indicating that OA performed poorer on the trials with different inter-hand frequency ratio than YA. The remaining interaction effects were not significant.

Following the results of the previous repeated measures ANOVA, which indicated that trials with non-iso inter-hand frequency ratio were more challenging than those with iso inter-hand frequency ratio for both age group, we averaged the error scores of the trials with the more difficult inter-hand frequency ratios (i.e., 3:1, 2:1, 1:2, and 1:3) and created one collapsed score, referred to as the average trial error score during the "non-iso" task conditions. Average of the error scores of the trials with the easier inter-hand frequency ratio (i.e., 1:1) was referred to as the average trial error score during the "iso" task conditions. Repeated measures ANOVA on the average trial error scores across all 7 days (Pre-test, training day 1-5 and Post-test) and across age groups (YA vs. OA) revealed significant main effects of age group $[F(1,46)=45.601, P<0.001]$, task condition $[F(1,46)=197.24, P<0.001]$, and day $[F(6,41)=36.51$, $P<0.001]$. These results indicate that trial error scores were higher in OA than YA, in the non-iso than iso condition, and performance improved across the 7 days in both age groups and task conditions (Fig. $3 b, c)$. The age group $\times$ task condition interaction was significant $[F(1,46)=15.34, P<0.001]$, indicating that average trial error score during the non-iso condition was higher in OA than YA. The age group $\times$ day interaction was significant $[F(6,41)=7.96, P<0.001]$, indicating a stronger improvement in OA compared with YA across days. The age group $\times$ task condition $\times$ day interaction was significant $[F(6,41)=2.57, P=0.033]$, indicating a stronger improvement in the non-iso condition in OA compared with YA across days.

On average, there was no significant difference between males and females in task performance across days $(P>0.05)$. Furthermore, t-test showed that Pre-to-Post performance improvements in both iso and non-iso task conditions were significantly higher in OA than in YA (both $P<0.001$ ).

\section{Age-Related Differences in Global Volume and Subregional Shape}

Univariate ANCOVA comparing global volume of the subcortical structures across age groups (i.e., hypothesis 2) revealed that OA, as compared with YA, had smaller global volume of the bilateral thalamus, putamen, nucleus accumbens, caudate, and left hippocampus (Table 1). No interaction effect of age group $\times$ gender was observed.

Additionally, we investigated age-related morphological differences (i.e., hypothesis 2) using the shape analysis approach. This analysis revealed widespread subregional deformations in the form of compression in OA, as compared with YA, in all the subcortical structures (Fig. 4). Furthermore, in OA as compared with YA, localized expansions were found in a few subregions within bilateral caudate (subregions subserving connectivity with executive and parietal cortices) and subicular and dentate gyrus subregions of the left hippocampus (Fig. 4).

\section{Association of Anatomical Measures with Training- Induced Performance Improvement}

\section{Global Volume Measures}

Table 2 summarizes results of the partial correlation (i.e., hypothesis 3: within group correlations) and regression analyses (i.e., hypothesis 4 : between group interactions) on the global volume of the subcortical structures. In this table, the correlation coefficients and beta values were compared
Table 1 Global volumes $\left(\mathrm{cm}^{3}\right)$ of the subcortical GM structures in YA and $O A$

\begin{tabular}{lccc}
\hline Subcortical structures & Mean (SD) & \multirow{2}{*}{$\begin{array}{l}\text { ANCOVA } \\
\text { P-value }\end{array}$} \\
\cline { 2 - 3 } & OA & YA & \\
\hline Left thalamus & $7196(623)$ & $8530(763)$ & $<0.001^{*}$ \\
Right thalamus & $7102(665)$ & $8338(809)$ & $<0.001^{*}$ \\
Left caudate & $3271(353)$ & $3880(439)$ & $<0.001^{*}$ \\
Right caudate & $3488(390)$ & $3972(471)$ & $0.009^{*}$ \\
Left putamen & $4605(415)$ & $5489(432)$ & $<0.001^{*}$ \\
Right putamen & $4717(473)$ & $5609(439)$ & $<0.001^{*}$ \\
Left pallidum & $1727(216)$ & $1835(185)$ & 0.55 \\
Right pallidum & $1770(224)$ & $1845(199)$ & 0.97 \\
Left hippocampus & $3687(400)$ & $4031(364)$ & $0.020^{*}$ \\
Right hippocampus & $3752(512)$ & $4029(477)$ & 0.30 \\
Left nucleus accumbens & $466(75)$ & $633(93)$ & $<0.001^{*}$ \\
Right nucleus accumbens & $331(84)$ & $556(79)$ & $<0.001^{*}$ \\
\hline
\end{tabular}

${ }^{*} \mathrm{P}$-value $<0.05$ (corrected for multiple comparison using FDR method).

between the iso and non-iso task conditions (i.e., hypothesis 5: task difficulty effect). In OA, Pre-to-Post performance improvement in the non-iso task condition was positively correlated with global volume of the right nucleus accumbens $(r=0.48$, $P=0.032)$. In other words, the larger the nucleus accumbens, the higher the performance improvement in OA (hypothesis 3). However, within this age group no significant correlation was observed between Pre-to-Post performance improvement in the easier iso task condition and global volume of the subcortical structures. In this age group, the Hotelling's T-square test revealed that for the left putamen $(Z=-2.27, P<0.05)$ and right nucleus accumbens $(Z=-2.07, P<0.05)$ the correlation coefficients differed significantly between the iso and non-iso task conditions (hypothesis 5). In YA, Pre-to-Post performance improvement in the non-iso task condition was negatively correlated with global volume of the right pallidum $(r=-0.44, P=$ $0.039)$ and right hippocampus $(r=-0.68, P<0.001)$ (hypothesis 3). Furthermore, Pre-to-Post performance improvement in the iso task condition negatively correlated with volume of the right hippocampus $(r=-0.53, P=0.014)$. In YA, no significant difference was found comparing the correlations coefficients between the iso and non-iso task conditions (hypothesis 5).

Multiple regression analyses revealed that global volume of the bilateral thalamus (left: $P=0.034$; right: $P=0.036$ ), right hippocampus $(P=0.045)$, and right nucleus accumbens $(P=$ 0.010) were differentially correlated with Pre-to-Post performance improvement in the non-iso task conditions across the age groups (hypothesis 4). In contrast, no interaction effect of age group $\times$ global volume (of the subcortical structures) was found for predicting Pre-to-Post performance improvement in the iso task condition. These findings indicate that the age effects were more pronounced in the more difficult (i.e., noniso) task conditions (hypothesis 5).

\section{Subregional Shape Measures}

In $\mathrm{OA}$, vertex-wise correlation analyses revealed positive correlations between Pre-to-Post performance improvement in the non-iso task conditions and subregional shape of the right thalamus $(r=0.73, P<0.001)$ (subregions subserving connectivity with the prefrontal, posterior parietal and temporal cortices), right putamen $(r=0.85, P<0.001)$ (subregions subserving connectivity with the limbic cortices), right nucleus accumbens $(r=$ $0.77, P<0.001$ ) (subregions subserving connectivity with the 


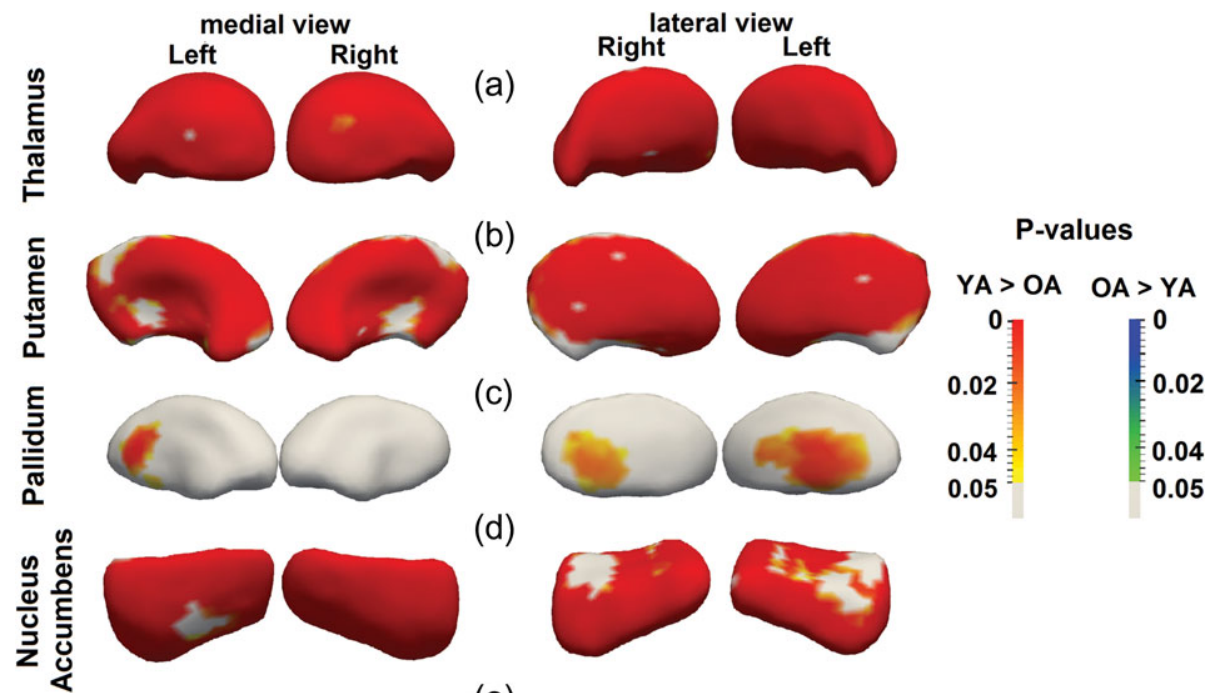

(e)
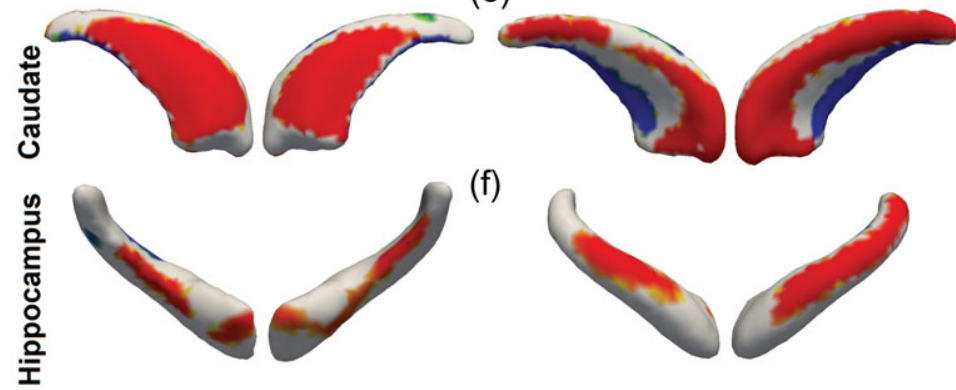

Figure 4. Vertex-wise comparison of (a) thalamus, (b) putamen, (c) pallidum, (d) nucleus accumbens, (e) caudate, and (f) hippocampus across YA and OA. Compared with YA, OA showed compressions in all the subcortical structures. Furthermore, OA, as compared with YA, showed subregional expansion in the caudate and hippocampus.

Table 2 Results of correlation analyses between Pre-to-Post performance improvement in the iso and non-iso task conditions and global volume of the motor-related subcortical structures within and across age groups

\begin{tabular}{|c|c|c|c|c|c|c|}
\hline \multirow[t]{3}{*}{ Subcortical structures } & \multirow{2}{*}{\multicolumn{2}{|c|}{$\begin{array}{l}\text { Within OA } \\
\text { Correlation coefficient }{ }^{\mathrm{a}} ; \\
\text { significance level }\end{array}$}} & \multicolumn{2}{|l|}{ Within YA } & \multirow{2}{*}{\multicolumn{2}{|c|}{$\begin{array}{l}\text { Age group interaction: Betab; } \\
\text { significance level }\end{array}$}} \\
\hline & & & \multicolumn{2}{|c|}{$\begin{array}{l}\text { Correlation coefficient }{ }^{\mathrm{a}} \text {; } \\
\text { significance level }\end{array}$} & & \\
\hline & Iso & Non-iso & Iso & Non-iso & Iso & Non-iso \\
\hline $\mathrm{L}$ thalamus & $0.06 ; \mathrm{ns}$ & $0.36 ; \mathrm{ns}$ & $-0.06 ; \mathrm{ns}$ & $-0.061 ; \mathrm{ns}$ & $-0.84 ; \mathrm{ns}$ & $-2.13 ; 0.03^{*}$ \\
\hline $\mathrm{R}$ thalamus & $-0.01 ; \mathrm{ns}$ & $0.31 ; \mathrm{ns}$ & $0.08 ; \mathrm{ns}$ & $-0.13 ; \mathrm{ns}$ & $-0.55 ; \mathrm{ns}$ & $-2.01 ; 0.04^{*}$ \\
\hline L caudate & $-0.19 ; \mathrm{ns}$ & $-0.11 ; \mathrm{ns}$ & $0.08 ; \mathrm{ns}$ & $0.18 ; \mathrm{ns}$ & $-0.25 ; \mathrm{ns}$ & $0.29 ; \mathrm{ns}$ \\
\hline$R$ caudate & $-0.42 ; \mathrm{ns}$ & $-0.33 ; \mathrm{ns}$ & $0.22 ; \mathrm{ns}$ & $0.08 ; \mathrm{ns}$ & $0.16 ; \mathrm{ns}$ & 0.76; ns \\
\hline L putamen & $-0.32 ; \mathrm{ns}$ & $0.09 ; \mathrm{ns}$ & $-0.15 ; \mathrm{ns}$ & $-0.27 ; \mathrm{ns}$ & $0.29 ; \mathrm{ns}$ & $-1.36 ; \mathrm{ns}$ \\
\hline R putamen & $-0.31 ; \mathrm{ns}$ & $-0.1 ; \mathrm{ns}$ & $-0.17 ; \mathrm{ns}$ & $-0.14 ; \mathrm{ns}$ & $0.15 ; \mathrm{ns}$ & $-0.35 ; \mathrm{ns}$ \\
\hline L pallidum & $-0.01 ; \mathrm{ns}$ & $0.12 ; \mathrm{ns}$ & $-0.08 ; \mathrm{ns}$ & $-0.34 ; \mathrm{ns}$ & $-0.36 ; \mathrm{ns}$ & $-0.77 ; \mathrm{ns}$ \\
\hline $\mathrm{R}$ pallidum & $0.12 ; \mathrm{ns}$ & $0.3 ; \mathrm{ns}$ & $-0.17 ; \mathrm{ns}$ & $-0.44 ; 0.04^{*}$ & $-0.54 ; \mathrm{ns}$ & $-1.15 ; \mathrm{ns}$ \\
\hline L hippocampus & $0.04 ; \mathrm{ns}$ & $0.21 ; \mathrm{ns}$ & $-0.41 ; \mathrm{ns}$ & $-0.3 ; \mathrm{ns}$ & $-0.80 ; \mathrm{ns}$ & $-1.11 ; \mathrm{ns}$ \\
\hline $\mathrm{R}$ hippocampus & $-0.06 ; \mathrm{ns}$ & $0.21 ; \mathrm{ns}$ & $-0.53 ; 0.01^{*}$ & $-0.68 ;<0.001^{*}$ & $-0.02 ; \mathrm{ns}$ & $-1.55 ; 0.05^{*}$ \\
\hline L nucleus accumbens & $0.06 ; \mathrm{ns}$ & $0.15 ; \mathrm{ns}$ & $-0.07 ; \mathrm{ns}$ & $-0.32 ; \mathrm{ns}$ & $-0.24 ; \mathrm{ns}$ & $-0.9 ; \mathrm{ns}$ \\
\hline $\mathrm{R}$ nucleus accumbens & $0.09 ; \mathrm{ns}$ & $0.48 ; 0.03^{*}$ & $-0.07 ; \mathrm{ns}$ & $-0.2 ; \mathrm{ns}$ & $-0.8 ; \mathrm{ns}$ & $-1.57 ; 0.01^{*}$ \\
\hline
\end{tabular}

${ }^{a}$ Correlation coefficient controlling for initial performance on Pre-test, TIV, and gender.

${ }^{b}$ Standardized beta value calculated using linear regression with Pre-to-Post performance improvement as dependent variable, and global volume of the subcortical structures, age group, and interaction of global volume $\times$ age group as independent variables, and initial performance on Pre-test, TIV, and gender as covariates. ${ }^{*}$ P-value $<0.05$ (uncorrected).

L, Left; R, Right; iso, trials with similar inter-hand frequency ratio (i.e., 1:1); non-iso, trials with different inter-hand frequency ratio (i.e., 1:2, 2:1, 1:3, and 3:1); ns, nonsignificant. 
limbic cortices), and right caudate $(r=0.64, P=0.002)$ (subregions subserving connectivity with the executive cortices) (Fig. 5a-d). These findings indicate that those subjects with more expanded subregions also showed higher Pre-to-Post performance improvement (hypothesis 3 ). In this age group, Preto-Post performance improvement in the iso task condition only showed positive correlations with subregional shape of the right thalamus (subregions subserving connectivity with prefrontal and temporal cortices).

In YA, vertex-wise correlation analyses revealed mostly negative correlations between Pre-to-Post performance improvement in the non-iso task conditions and subregional shape of the cornu ammonis (CA1-3) and subicular subregions of the right hippocampus $(r=-0.68, P=0.001)$ (Fig. 5e). This finding implies that larger Pre-to-Post performance improvement was associated with smaller subregions (hypothesis 3). In this age group, Pre-to-Post performance improvement in the iso task condition showed no correlation with the shape of any of the subcortical structures.

Vertex-wise interaction analyses (hypothesis 4) were performed using the scores from the non-iso and iso task conditions, separately. Regarding the non-iso task condition, these analyses revealed greater associations in OA than in YA between Pre-to-Post performance improvement in the non-iso task conditions and subregional shape of the left thalamus (subregions subserving connectivity with prefrontal, posterior parietal, premotor, and temporal cortices), left putamen (subregions subserving connectivity with rostral and caudal motor and limbic cortices), right putamen (subregions subserving connectivity with rostral motor, executive, and temporal cortices), and bilateral nucleus accumbens (subregions subserving connectivity with limbic cortices) (Figs 6 and 7). With regard to the iso task condition, greater associations were found in OA as compared with YA between Pre-to-Post performance improvement in the iso task condition and subregional shape of the right thalamus (subregions subserving connectivity with sensory, primary motor, premotor, and posterior parietal cortices), right caudate (subregions subserving connectivity with executive and limbic cortices), right putamen (subregions subserving connectivity with rostral motor cortex), and right and left nucleus accumbens (subregions subserving connectivity with limbic cortices) (Fig. 8). Altogether, the interaction results imply that the effects observed in the subregional shape of the left thalamus, putamen, and accumbens were more specific to the training-induced improvement in the more difficult (i.e., non-iso) task conditions (hypothesis 5).

\section{Discussion}

In this study, we investigated the neuroanatomical correlates of variation in bimanual skill acquisition in YA and OA. Furthermore, we used the shape analysis approach for the first time to explore age-dependent associations between training-induced performance improvement and subregional shape of the medial subcortical GM structures. Our behavioral results showed that $\mathrm{OA}$, as compared with YA, performed poorer on the bimanual coordination task across all training days (hypothesis 1), but they demonstrated a greater performance improvement. Our volumetric and shape analyses indicated an age-related difference between OA and YA in global volume and subregional shape of the studied subcortical structures (hypothesis 2). In OA, global volume of the right nucleus accumbens and subregional shape of the right thalamus, putamen, nucleus accumbens, and caudate were positively correlated (hypothesis 3 ) with training-induced performance improvement in the more difficult task conditions, whereby the 2 hands moved with different cycling frequencies (i.e., non-iso tasks). In contrast, in YA, global volume of the right pallidum and right hippocampus and subregional shape of the right hippocampus were negatively correlated with performance
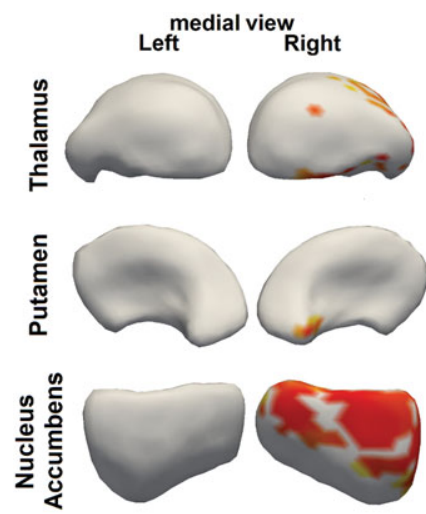

(e)

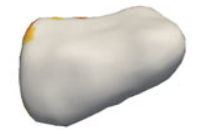

(a)

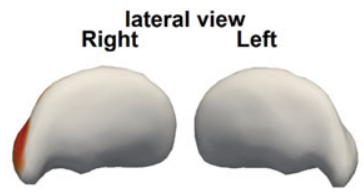

(b)

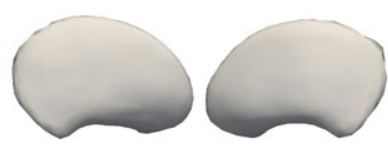

(d)
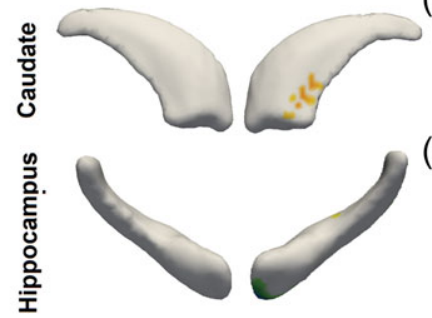

(e)
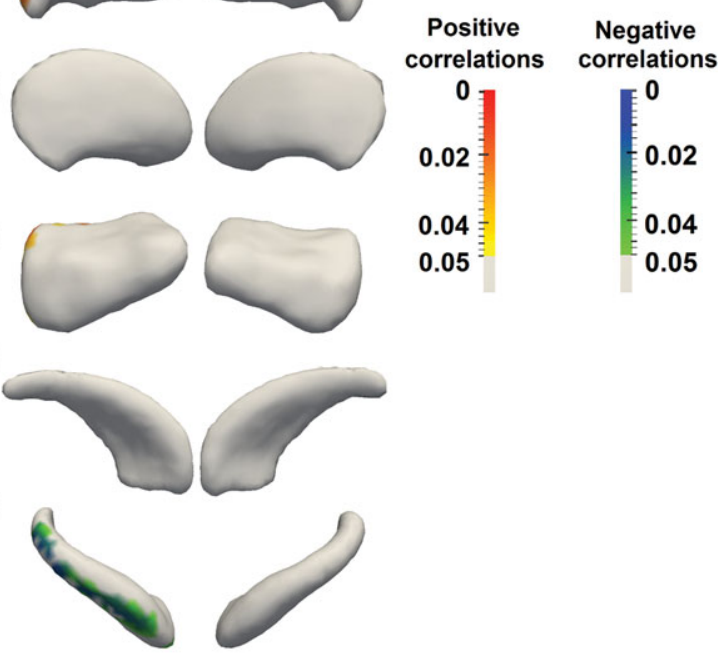

Figure 5. Vertex-wise correlations with Pre-to-Post performance improvement in the non-iso task conditions in different age groups. In OA, subregions within the (a) right thalamus, (b) right putamen, (c) right nucleus accumbens, and (d) right caudate showed significant positive correlations with Pre-to-Post performance improvement in the non-iso task conditions. However, in YA, subregions within the (e) right hippocampus were negatively correlated with Pre-to-Post performance improvement in the non-iso task condition. Iso, trials with similar inter-hand frequency ratio (i.e., 1:1); non-iso, trials with different inter-hand frequency ratio (i.e., $1: 2,2: 1,1: 3$, and $3: 1$ ). 


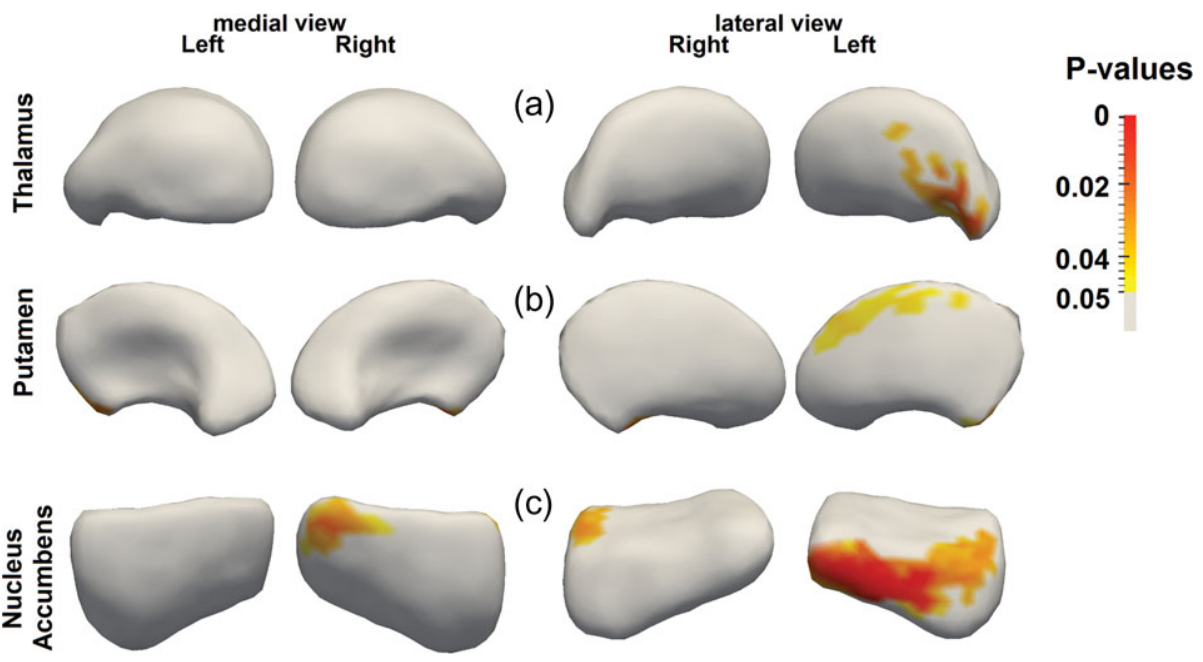

Figure 6. Vertex-wise interaction analyses between age group and Pre-to-Post performance improvement in the non-iso task conditions. OA showed greater associations than YA between Pre-to-Post performance improvement in the non-iso task conditions and subregional shape of the (a) left thalamus, (b) bilateral putamen, and (c) bilateral nucleus accumbens. Non-iso, trials with different inter-hand frequency ratio (i.e., 1:2, 2:1, 1:3, and 3:1).
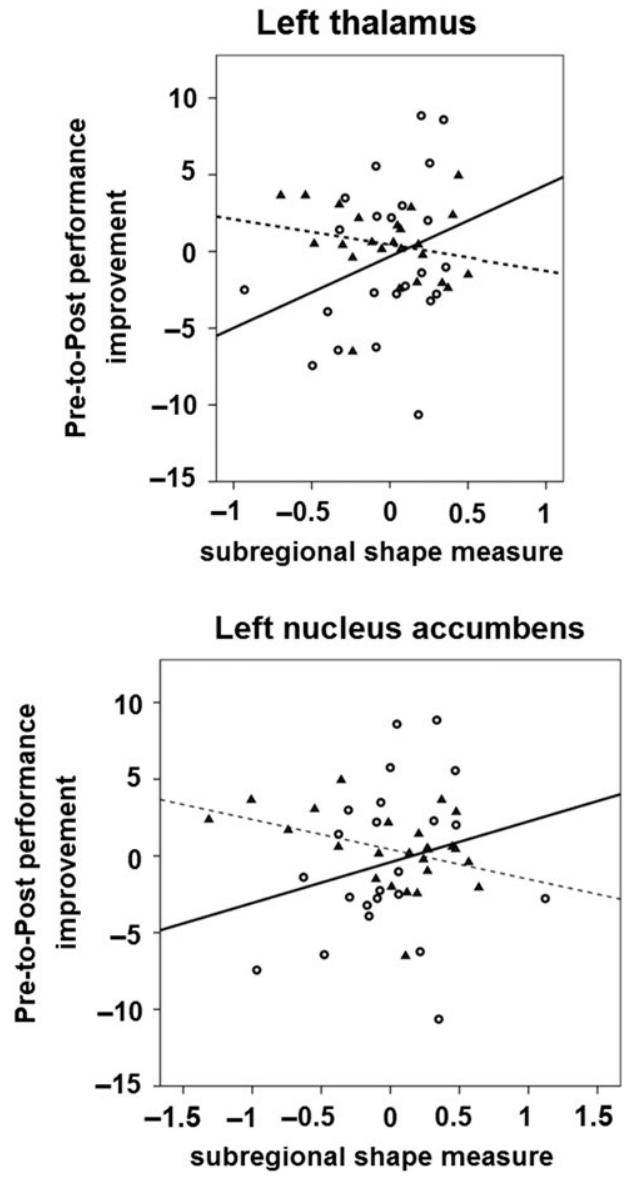
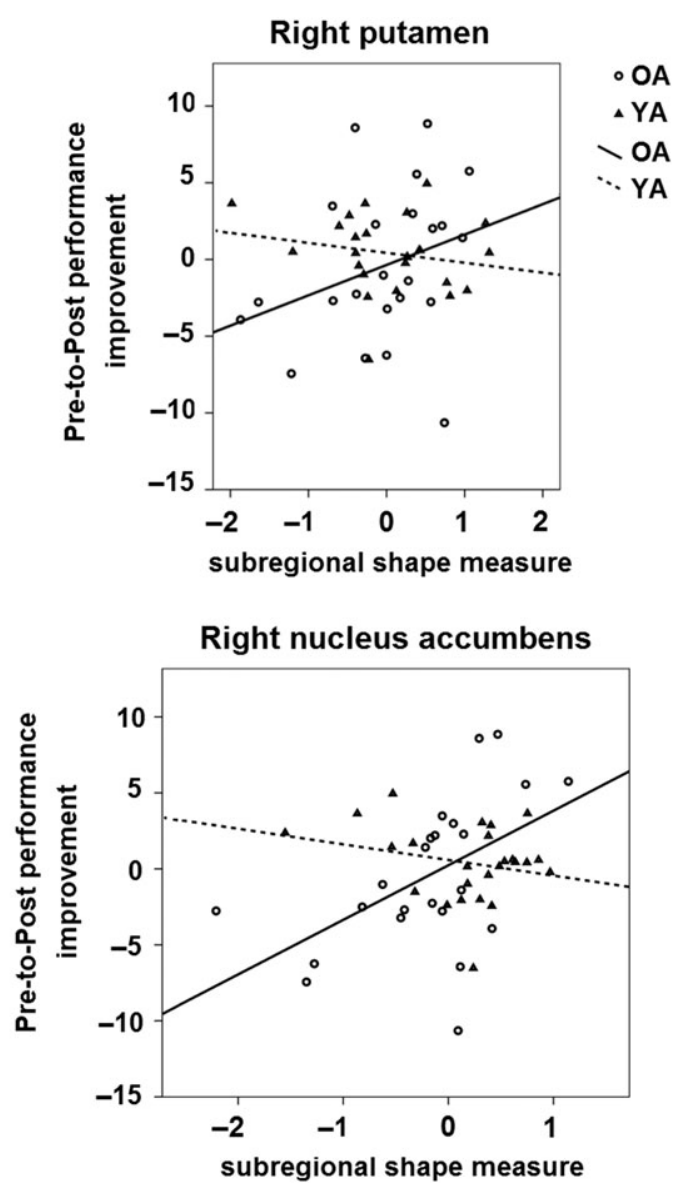

Figure 7. Scatter plots showing that Pre-to-Post performance improvement in the non-iso task conditions (controlled for performance at Pre-test) was differentially correlated with subregional shape measures of the voxels within the left thalamus, right putamen, and bilateral nucleus accumbens (controlled for the TIV) across YA and OA. Non-iso, trials with different inter-hand frequency ratio (i.e., 1:2, 2:1, 1:3, and 3:1).

improvement in these more difficult task conditions. Furthermore, the interaction analyses revealed that global volume of the bilateral thalamus, right nucleus accumbens and hippocampus and subregional shape of the left thalamus, putamen and accumbens demonstrated differential associations with performance improvement across age groups (hypothesis 4). Our findings not only indicate that pre-existing anatomical features of these subcortical areas partially account for the variations in 

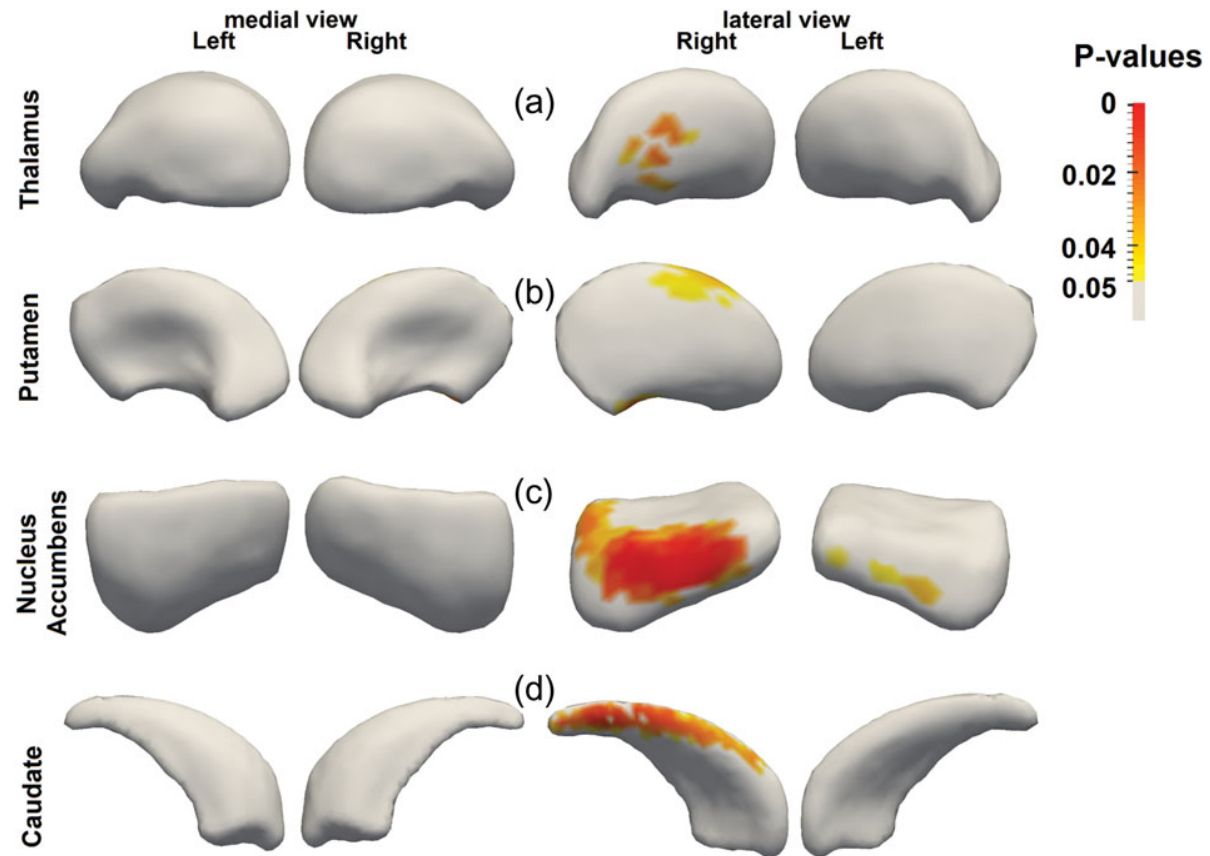

(d)

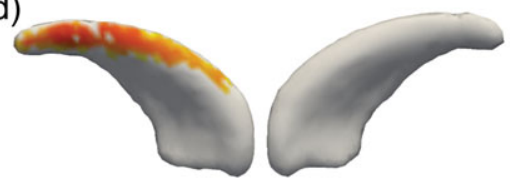

Figure 8. Vertex-wise interaction analyses between age group and Pre-to-Post performance improvement in the iso task conditions. OA showed greater associations than YA between Pre-to-Post performance improvement in the iso task conditions and subregional shape of the (a) left thalamus, (b) bilateral putamen, and (c) bilateral nucleus accumbens. Iso, trials with similar inter-hand frequency ratio (i.e., 1:1).

training-induced performance improvement, but also suggest that the role of the thalamus, putamen, nucleus accumbens and hippocampus is age-dependent.

\section{Training-Induced Behavioral Changes}

Performance level on the bimanual coordination task was generally lower in OA as compared with YA. This finding is in agreement with hypothesis 1 and previous reports demonstrating an age-related decline in motor skill performance (Swinnen et al. 1998; Wishart et al. 2000; Voelcker-Rehage 2008; Seidler et al. 2010; Sleimen-Malkoun et al. 2013). Furthermore, relative to YA, OA showed greater performance improvement, which may be accounted for by a lower initial level of performance in $\mathrm{OA}$ at Pre-test, providing a larger window for performance improvement. These findings are consistent with the hypothesis that even though aging is associated with diminished accuracy and speed in motor performance, OA are still able to acquire new skills and improve through practice (Durkina et al. 1995; Rodrigue et al. 2005; King et al. 2013). The question is whether the age-related brain atrophy may hamper their learning capabilities, as discussed next.

\section{Age-Related Differences in Global and Subregional Subcortical Anatomy}

With regard to the brain anatomical measures, OA as compared with YA showed smaller global volume and widespread subregional compressions in several medial subcortical structures. Furthermore, subregional expansions were found within the bilateral caudate and left hippocampus. However, the number of voxels showing compression was consistently higher than the number of voxels showing expansion. These findings are in accordance with hypothesis 2 , which was based on previous reports indicating age-related degeneration of subcortical GM structures (Raz et al. 2000, 2005; Walhovd et al. 2005; Cherubini et al. 2009; Goodro et al. 2012; Fjell et al. 2013; Inano et al. 2013; Serbruyns et al. 2015). With regard to the pallidum, although its global volume did not differ significantly between OA and YA, shape analysis indicated subregional bilateral compressions in OA. Findings regarding age-related pallidal volume changes have been inconsistent so far. While some volumetric studies have reported age-related pallidal atrophy (Goodro et al. 2012; Fjell et al. 2013; Jäncke et al. 2015), others did not report such atrophy (Walhovd et al. 2005; Cherubini et al. 2009; Inano et al. 2013). In a recent aging study, Serbruyns et al. (2015) reported that atrophy of the bilateral pallidum does not start before the seventh decade of life. Therefore, results of our shape analysis are in agreement with the latter study as OA in our study were all over 60 years of age.

Even though the exact neurobiological underpinnings of the observed subregional deformations (i.e., mostly compression but also some expansions) in OA are still unclear, some tentative mechanisms for future investigation are proposed, as discussed next.

First, subregional compressions observed in OA can be attributed to subregional neuronal shrinkage and loss (Haug et al. 1984; Simić et al. 1997), loss of intralaminar myelin (Courchesne et al. 2000), or loss of dendritic arborization (Jacobs et al. 1997). Compression in the striatum can be linked to the age-related loss of dopaminergic receptors (Volkow et al. 1998) or loss of the neostriatal source neurons (i.e., substania nigra, pars compacta) (Alheid et al. 1990). Second, converging evidence from crosssectional and longitudinal developmental studies indicates that aging is associated with enlargement of the cerebrospinal fluid (CSF)-filled spaces (including sulci, fissures, and ventricles) that occur at the expense of GM volume (Pfefferbaum et al. 1994; Resnick et al. 2003). Therefore, it is equally possible that enlargement of the CSF-filled spaces (including ventricles) is responsible for the subregional compressions observed in the subcortical 
structures. Consistently, further exploratory analyses in the present study revealed enlarged total ventricular volume (extracted using FreeSurfer) in OA, as compared with YA $(P<0.001)$. Furthermore, partial correlation between total ventricular volume and total GM volume, controlled for TIV, showed a trend towards a significant negative correlation in OA $(r=-0.412$; $P=0.057)$, while this effect was non-significant in YA $(r=-0.312$; $P=0.138)$. Third, it has been speculated that subregional expansions (as observed in the caudate and hippocampus) may indirectly relate to the compensatory mechanisms implemented by $\mathrm{OA}$ to overcome their emerging structural brain atrophy (Serbruyns et al. 2015) but supportive experimental evidence is currently lacking. Nevertheless, the results of this morphometric study alone fail to determine the causal factors for the observed effect. Future histological studies combined with structural imaging studies can provide a better picture for the true neurobiological underpinnings of the observed subcortical deformations in OA.

\section{Relationship Between Pre-Training Global and Subregional Subcortical Anatomy and Training-Induced Performance Improvement}

Our most important finding was the association between training-induced performance improvement and global volume as well as subregional shape of the subcortical structures, within (hypothesis 3) and between (hypothesis 4) age groups. Interestingly, the associations were more pronounced for performance improvement during the more difficult (i.e., non-iso) as opposed to the easy (i.e., iso) task conditions (hypothesis 5). This is not surprising because the iso task conditions refer to the preferred motor coordination repertoire (i.e., in-phase and anti-phase patterns) whereas the non-iso task conditions deviate from these intrinsic coordination modes and thus leave more room for learning (Swinnen 2002; Swinnen and Wenderoth 2004). Furthermore, these associations were found to be age-dependent for several subcortical structures (hypothesis 4). Specifically, in OA, we found positive associations between performance improvement in the more difficult task conditions and global volume of the nucleus accumbens and subregional shape of the right thalamus, putamen, caudate and nucleus accumbens. These findings are consistent with previous literature on the functional role of these structures. The thalamus serves as a relay station, receiving inputs from various structures, including the cerebellum and basal ganglia, and transfers this information to a large part of the cortical surface, including the sensorimotor areas (Behrens et al. 2003). The role of the thalamus in the control of bimanual movements and in learning new bimanual skills has been well documented (Debaere et al. 2004a, 2004b; Aramaki et al. 2006; Wenderoth et al. 2006; Wu et al. 2010; Ng et al. 2013). Moreover, age-related atrophy in the thalamus has shown to contribute to bimanual performance decline on the Purdue pegboard task (Serbruyns et al. 2015). Thus, those OA whose thalamus underwent a greater extent of compression also showed a lower rate of bimanual skill learning.

The putamen and caudate have also been assigned important functions in motor sequence learning and bimanual skill learning (Graybiel 1995; Salmon and Butters 1995; Hikosaka et al. 1999; Debaere et al. 2004a; Doyon and Benali 2005; Puttemans et al. 2005; Halsband and Lange 2006; Haruno and Kawato 2006). In line with our results, volumetric studies have reported that volume of these dorsal striatal structures can predict (motor) performance and learning outcome (Kennedy and Raz 2005; Erickson et al. 2010).
With regard to the ventral striatum, preclinical, and human learning studies have implicated the nucleus accumbens in motivation, reward and spatial learning, memory, selection of flexible behavior, and translation of motivation into motor actions (Mogenson et al. 1980; Hernandez et al. 2002; O'Doherty et al. 2004; Roitman et al. 2005; Atallah et al. 2007; Humphries and Prescott 2010; Rinaldi et al. 2012; Floresco 2015; Boisgontier et al. 2016). Global volume of the nucleus accumbens has been shown to predict progress in learning a video game in YA (Erickson et al. 2010). The nucleus accumbens is a major target region of dopamine neurons in the brain (Haber et al. 2000) and it receives inputs from the substantia nigra and ventral tegmental area dopaminergic neurons. Dopamine decline, occurring as part of the normal aging process (Fearnley and Lees 1991; Bäckman et al. 2006; Düzel et al. 2010; Vaillancourt et al. 2012), has been associated with deficits in motor function (Volkow et al. 1998), decision-making and reward anticipation (Schott et al. 2007; Samanez-Larkin et al. 2011; Chowdhury et al. 2013). Our findings may indirectly suggest that the thalamus, putamen, and caudate, which are involved in motorrelated processes, as well as the nucleus accumbens, which regulates reward- and motivation-related processes, are important structures in $\mathrm{OA}$ for successful learning of motor (including bimanual) skills.

In OA, significant subregional correlations with behavior were found in the thalamic subregions (which have connections with the prefrontal, posterior parietal and temporal cortices), in the putamen and nucleus accumbens subregions (subserving connectivity with the limbic cortices) and in the caudate subregions (which have connections with executive cortices). These connectivity profiles extend beyond the sensorimotor pathways that one would typically expect in motor control tasks. In this respect, it is important to note that the complex bimanual visuomotor tracking task set we used here engaged several cognitive and motor functions, such as attention, task selection, error correction, motor execution, memory, and learning (Beets et al. 2015). Therefore, it is not surprising to find correlations with subregions which are associated with non-motor functions. In fact, using a similar task set, Sisti et al. (2012) reported in YA that WM microstructural organization of the genu of the corpus callosum, which connects the interhemispheric prefrontal cortices, was highly correlated with training-induced change in the bimanual task.

In YA, smaller hippocampal volume was associated with better motor skill acquisition. This finding might seem puzzling at first glance, as converging evidence yields that the hippocampus is involved in declarative and spatial memory formation, maintenance, and retrieval (Bohbot et al. 1998; Small et al. 2001) and acquisition and consolidation of motor sequence memory (Albouy et al. 2008, 2013) and it is generally assumed that a larger hippocampus correlates with better performance. However, our finding is in accordance with several imaging studies investigating memory ability in YA. It has been reported that while in older populations (Hackert et al. 2002; Head et al. 2008) and patients with neurological disorders (Videbech and Ravnkilde 2004; Schuff et al. 2009), smaller hippocampal volume effectively predicts poorer memory, findings in young participants with no neurological disorders have been inconsistent and have provided little support for the hypothesis that "bigger is always better" (for a review, see Van Petten 2004). In fact, several studies in children, adolescents and YA have supported the hypothesis that with regard to the relation between hippocampal size and memory, "smaller is better" (Chantôme et al. 1999; Foster et al. 1999; Sowell et al. 2001; Pruessner et al. 2007). 
Although the neurobiological mechanism underlying this negative association is still unclear, it has been hypothesized that insufficient and abnormal pruning of the hippocampus following neural development during childhood and adolescence may lead to poorer memory efficiency (Foster et al. 1999). Similarly, in YA, hippocampal size might exhibit a negative relationship with motor learning.

Although anticipated, another interesting finding of the present study is the fact that the shape analysis approach detected more subtle effects than the conventional volumetric analysis (i.e., hypothesis 6). This confirms previous studies showing that shape analysis could provide more detailed information about the location of the effects (Patenaude et al. 2011; Menke et al. 2014; Serbruyns et al. 2015).

Even though the results of our shape and volumetric analyses partially converged, it is worth mentioning that this was not the case for all results. The most consistent findings, however, were related to the right nucleus accumbens for which both analysis techniques indicated: 1) a smaller volume in the OA (between group comparisons), 2) significant morphological correlations with performance improvement in the difficult task variant in OA (within group correlations), and 3) greater brainbehavior associations in OA than in YA (interaction effect analysis). While it is not possible to draw direct conclusions from these findings, they might indirectly indicate that in a population with sub-optimal brain function (i.e., OA), the nucleus accumbens becomes more important in learning complex motor tasks (such as the one used in this study). As nucleus accumbens is involved in reinforcement processes during learning, our findings may imply that OA with less atrophy of nucleus accumbens are more effective in learning these types of tasks.

Some limitations of this study should be noted. First, successful performance of a complex bimanual coordination tasks requires a network of brain regions including the (pre)frontal, motor, and parietal cortices as well as the subcortical structures and cerebellum (Beets et al. 2015). However, here we chose to focus only on the association between motor skill acquisition and subcortical structures. The reason for this decision was to investigate brain-behavior associations using a novel approach, that is, subcortical shape analysis, which has been suggested to be more sensitive in detecting small and subregional effects than the conventional volumetric approaches (Menke et al. 2014; Serbruyns et al. 2015). Second, as healthy aging has also been associated with global and regional cortical atrophy (Salat et al. 2004), future volumetric studies should also consider the contribution of aging-related cortical thinning in motor skill acquisition decline. This issue might raise the question whether general cortical morphometric changes better predict motor learning performance improvement. To further investigate this matter and ensure that our regression findings represent genuine effects, we repeated the regression analyses using total GM volume (instead of TIV) as a covariate. These analyses yielded that the significant interaction effects were the same as the ones reported in the Results section: left thalamus (Beta $=-2.12$; $P=0.036$ ), right thalamus (Beta $=-2.01 ; P=0.036$ ), right nucleus accumbens (Beta $=-1.35 ; P=0.017$ ), and right hippocampus (Beta $=-1.48 ; P=0.05)$. These results highlight the specificity of the interaction effects for this complex bimanual task.

In sum, our findings demonstrate that variation in the structure of the subcortical structures involved in motor learning and motivation/reward partially account for variations in skill acquisition potential in YA and OA. More specifically, we found that global volume of the thalamus, caudate, putamen, nucleus accumbens, and hippocampus, and subregional shape of the thalamus, putamen, and nucleus accumbens "differentially" predicted motor learning outcome in YA and OA. These findings are consistent with previous functional activation studies, showing the importance of subcortical structures in neuroplasticity and motor skill acquisition potential in different age groups.

\section{Funding}

This work was supported by the Research Foundation-Flanders (Fonds Wetenschappelijk Onderzoek (FWO) Vlaanderen) (G0708.14); Interuniversity Attraction Poles Programme initiated by the Belgian Science Policy Office (P7/11); KU Leuven Research Fund (C16/15/070); A post-doctoral fellowship FWO research grant $(1504015 \mathrm{~N})$ to MPB; A post-doctoral mandate internal grant by KU Leuven (PDM/16/168) to HZA.

\section{Notes}

Conflict of Interest: None declared.

\section{References}

Albouy G, King BR, Maquet P, Doyon J. 2013. Hippocampus and striatum: dynamics and interaction during acquisition and sleep-related motor sequence memory consolidation. Hippocampus. 23:985-1004.

Albouy G, Sterpenich V, Balteau E, Vandewalle G, Desseilles M, Dang-Vu T, Darsaud A, Ruby P, Luppi P-H, Degueldre C, et al. 2008. Both the hippocampus and striatum are involved in consolidation of motor sequence memory. Neuron. 58: 261-272.

Alheid G, Switzer R, Heimer L. 1990. Basal ganglia. In: Paxinos GT, editors. The human nervous system. Academic Press, San Diego, CA. p. 483-582.

Aramaki Y, Honda M, Okada T, Sadato N. 2006. Neural correlates of the spontaneous phase transition during bimanual coordination. Cereb Cortex. 16:1338-1348.

Atallah HE, Lopez-Paniagua D, Rudy JW, O'Reilly RC. 2007. Separate neural substrates for skill learning and performance in the ventral and dorsal striatum. Nat Neurosci. 10: 126-131.

Bäckman L, Nyberg L, Lindenberger U, Li S-C, Farde L. 2006. The correlative triad among aging, dopamine, and cognition: current status and future prospects. Neurosci Biobehav Rev. 30:791-807.

Ballmaier M, Narr KL, Toga AW, Elderkin-Thompson V, Thompson PM, Hamilton L, Haroon E, Pham D, Heinz A, Kumar A. 2008. Hippocampal morphology and distinguishing late-onset from early-onset elderly depression. Am J Psychiatry. 165:229-237.

Beets IAM, Gooijers J, Boisgontier MP, Pauwels L, Coxon JP, Wittenberg G, Swinnen SP. 2015. Reduced neural differentiation between feedback conditions after bimanual coordination raining with and without augmented visual feedback. Cereb Cortex. 25:1958-1969.

Behrens TEJ, Johansen-Berg $\mathrm{H}$, Woolrich MW, Smith SM, Wheeler-Kingshott CAM, Boulby PA, Barker GJ, Sillery EL, Sheehan K, Ciccarelli O, et al. 2003. Non-invasive mapping of connections between human thalamus and cortex using diffusion imaging. Nat Neurosci. 6:750-757.

Belin D, Everitt BJ. 2008. Cocaine seeking habits depend upon dopamine-dependent serial connectivity linking the ventral with the dorsal striatum. Neuron. 57:432-441. 
Bohbot VD, Kalina M, Stepankova K, Spackova N, Petrides M, Nadel L. 1998. Spatial memory deficits in patients with lesions to the right hippocampus and to the right parahippocampal cortex. Neuropsychologia. 36:1217-1238.

Boisgontier MP, van Ruitenbeek P, Leunissen I, Chalavi S, Sunaert S, Levin O, Swinnen SP. 2016. Nucleus accumbens and caudate atrophy predicts longer action selection times in young and old adults. Hum Brain Mapp. 37:4629-4639.

Brosseau J, Potvin M-J, Rouleau I. 2007. Aging affects motor skill learning when the task requires inhibitory control. Dev Neuropsychol. 32:597-613.

Cai L, Chan JSY, Yan JH, Peng K. 2014. Brain plasticity and motor practice in cognitive aging. Front Aging Neurosci. 6:1-12.

Chantôme M, Perruchet P, Hasboun D, Dormont D, Sahel M, Sourour N, Zouaoui A, Marsault C, Duyme M. 1999. Is there a negative correlation between explicit memory and hippocampal volume? NeuroImage. 10:589-595.

Cherubini A, Péran P, Caltagirone C, Sabatini U, Spalletta G. 2009. Aging of subcortical nuclei: microstructural, mineralization and atrophy modifications measured in vivo using MRI. NeuroImage. 48:29-36.

Chowdhury R, Guitart-Masip M, Lambert C, Dayan P, Huys Q Düzel E, Dolan RJ. 2013. Dopamine restores reward prediction errors in old age. Nat Neurosci. 16:648-653.

Coscia DM, Narr KL, Robinson DG, Hamilton LS, Sevy S, Burdick KE, Gunduz-Bruce H, McCormack J, Bilder RM, Szeszko PR. 2009. Volumetric and shape analysis of the thalamus in first-episode schizophrenia. Hum Brain Mapp. 30:1236-1245.

Courchesne E, Chisum HJ, Townsend J, Cowles A, Covington J, Egaas B, Harwood M, Hinds S, Press GA. 2000. Normal brain development and aging: quantitative analysis at in vivo MR imaging in healthy volunteers. Radiology. 216:672-682.

De Martino B, Kumaran D, Holt B, Dolan RJ. 2009. The neurobiology of reference-dependent value computation. J Neurosci. 29:3833-3842.

Debaere F, Wenderoth N, Sunaert S, Van Hecke P, Swinnen SP. 2003. Internal vs external generation of movements: differential neural pathways involved in bimanual coordination performed in the presence or absence of augmented visual feedback. NeuroImage. 19:764-776.

Debaere F, Wenderoth N, Sunaert S, Van Hecke P, Swinnen SP. 2004a. Changes in brain activation during the acquisition of a new bimanual coodination task. Neuropsychologia. 42:855-867.

Debaere F, Wenderoth N, Sunaert S, Van Hecke P, Swinnen SP. 2004b. Cerebellar and premotor function in bimanual coordination: parametric neural responses to spatiotemporal complexity and cycling frequency. NeuroImage. 21:1416-1427.

Della-Maggiore V, Scholz J, Johansen-Berg H, Paus T. 2009. The rate of visuomotor adaptation correlates with cerebellar white-matter microstructure. Hum Brain Mapp. 30:4048-4053.

Desrosiers J, Hébert R, Bravo G, Rochette A. 1999. Age-related changes in upper extremity performance of elderly people: a longitudinal study. Exp Gerontol. 34:393-405.

Doyon J, Benali H. 2005. Reorganization and plasticity in the adult brain during learning of motor skills. Curr Opin Neurobiol. 15:161-167.

Doyon J, Penhune V, Ungerleider LG. 2003. Distinct contribution of the cortico-striatal and cortico-cerebellar systems to motor skill learning. Neuropsychologia. 41:252-262.

Doyon J, Song AW, Karni A, Lalonde F, Adams MM, Ungerleider LG. 2002. Experience-dependent changes in cerebellar contributions to motor sequence learning. Proc Natl Acad Sci USA. 99:1017-1022.
Durkina M, Prescott L, Furchtgott E, Cantor J, Powell DA. 1995. Performance but not acquisition of skill learning is severely impaired in the elderly. Arch Gerontol Geriatr. 20:167-183.

Düzel E, Bunzeck N, Guitart-Masip M, Düzel S. 2010. Noveltyrelated motivation of anticipation and exploration by dopamine (NOMAD): implications for healthy aging. Neurosci Biobehav Rev. 34:660-669.

Erickson KI, Boot WR, Basak C, Neider MB, Prakash RS, Voss MW, Graybiel AM, Simons DJ, Fabiani M, Gratton G, et al. 2010. Striatal volume predicts level of video game skill acquisition. Cereb Cortex. 20:2522-2530.

Fearnley JM, Lees AJ. 1991. Ageing and Parkinson's disease: substantia nigra regional selectivity. Brain J Neurol. 114:2283-2301.

Fjell AM, Westlye LT, Grydeland H, Amlien I, Espeseth T, Reinvang I, Raz N, Holland D, Dale AM, Walhovd KB, Alzheimer Disease Neuroimaging Initiative. 2013. Critical ages in the life course of the adult brain: nonlinear subcortical aging. Neurobiol Aging. 34:2239-2247.

Floresco SB. 2015. The nucleus accumbens: an interface between cognition, emotion, and action. Annu Rev Psychol. 66:25-52.

Foster JK, Meikle A, Goodson G, Mayes AR, Howard M, Sünram SI, Cezayirli E, Roberts N. 1999. The hippocampus and delayed recall: bigger is not necessarily better? Memory. 7:715-732.

Fozard JL, Vercryssen M, Reynolds SL, Hancock PA, Quilter RE. 1994. Age differences and changes in reaction time: the Baltimore longitudinal study of aging. J Gerontol. 49: P179-P189.

Goodro M, Sameti M, Patenaude B, Fein G. 2012. Age effect on subcortical structures in healthy adults. Psychiatry Res. 203: 38-45.

Graybiel AM. 1995. Building action repertoires: memory and learning functions of the basal ganglia. Curr Opin Neurobiol. 5:733-741.

Graybiel AM. 2008. Habits, rituals, and the evaluative brain. Annu Rev Neurosci. 31:359-387.

Haber SN, Fudge JL, McFarland NR. 2000. Striatonigrostriatal pathways in primates form an ascending spiral from the shell to the dorsolateral striatum. J Neurosci. 20:2369-2382.

Hackert VH, den Heijer T, Oudkerk M, Koudstaal PJ, Hofman A, Breteler MMB. 2002. Hippocampal head size associated with verbal memory performance in nondemented elderly. NeuroImage. 17:1365-1372.

Halsband U, Lange RK. 2006. Motor learning in man: a review of functional and clinical studies. J Physiol Paris. 99:414-424.

Haruno M, Kawato M. 2006. Different neural correlates of reward expectation and reward expectation error in the putamen and caudate nucleus during stimulus-actionreward association learning. J Neurophysiol. 95:948-959.

Haug H, Kühl S, Mecke E, Sass NL, Wasner K. 1984. The significance of morphometric procedures in the investigation of age changes in cytoarchitectonic structures of human brain. J Hirnforsch. 25:353-374.

Head D, Rodrigue KM, Kennedy KM, Raz N. 2008. Neuroanatomical and cognitive mediators of age-related differences in episodic memory. Neuropsychology. 22:491-507.

Hernandez PJ, Sadeghian K, Kelley AE. 2002. Early consolidation of instrumental learning requires protein synthesis in the nucleus accumbens. Nat Neurosci. 5:1327-1331.

Hikosaka O, Nakahara H, Rand MK, Sakai K, Lu X, Nakamura K, Miyachi S, Doya K. 1999. Parallel neural networks for learning sequential procedures. Trends Neurosci. 22:464-471.

Humphries MD, Prescott TJ. 2010. The ventral basal ganglia, a selection mechanism at the crossroads of space, strategy, and reward. Prog Neurobiol. 90:385-417. 
Inano S, Takao H, Hayashi N, Yoshioka N, Mori H, Kunimatsu A, Abe O, Ohtomo K. 2013. Effects of age and gender on neuroanatomical volumes. J Magn Reson Imaging. 37:1072-1076.

Jacobs B, Driscoll L, Schall M. 1997. Life-span dendritic and spine changes in areas 10 and 18 of human cortex: a quantitative Golgi study. J Comp Neurol. 386:661-680.

Jäncke L, Mérillat S, Liem F, Hänggi J. 2015. Brain size, sex, and the aging brain. Hum Brain Mapp. 36:150-169.

Johansen-Berg H, Behrens TEJ, Sillery E, Ciccarelli O, Thompson AJ, Smith SM, Matthews PM. 2005. Functional-anatomical validation and individual variation of diffusion tractography-based segmentation of the human thalamus. Cereb Cortex. 15:31-39.

Johansen-Berg H, Della-Maggiore V, Behrens TEJ, Smith SM, Paus T. 2007. Integrity of white matter in the corpus callosum correlates with bimanual co-ordination skills. NeuroImage. 36 (Suppl 2):T16-T21.

Joseph J, Warton C, Jacobson SW, Jacobson JL, Molteno CD, Eicher A, Marais P, Phillips OR, Narr KL, Meintjes EM. 2014. Three-dimensional surface deformation-based shape analysis of hippocampus and caudate nucleus in children with fetal alcohol spectrum disorders. Hum Brain Mapp. 35:659-672.

Jueptner M, Frith CD, Brooks DJ, Frackowiak RS, Passingham RE. 1997a. Anatomy of motor learning. II. Subcortical structures and learning by trial and error. J Neurophysiol. 77:1325-1337.

Jueptner M, Stephan KM, Frith CD, Brooks DJ, Frackowiak RSJ, Passingham RE. 1997b. Anatomy of motor learning. I. Frontal cortex and attention to action. J Neurophysiol. 77: 1313-1324.

Kennedy KM, Raz N. 2005. Age, sex and regional brain volumes predict perceptual-motor skill acquisition. Cortex. 41:560-569.

King BR, Fogel SM, Albouy G, Doyon J. 2013. Neural correlates of the age-related changes in motor sequence learning and motor adaptation in older adults. Front Hum Neurosci. 7:142.

Kraft E, Chen AW, Flaherty AW, Blood AJ, Kwong KK, Jenkins BG. 2007. The role of the basal ganglia in bimanual coordination. Brain Res. 1151:62-73.

Lehéricy S, Benali H, Van de Moortele P-F, Pélégrini-Issac M, Waechter T, Ugurbil K, Doyon J. 2005. Distinct basal ganglia territories are engaged in early and advanced motor sequence learning. Proc Natl Acad Sci USA. 102:12566-12571.

Menke RAL, Szewczyk-Krolikowski K, Jbabdi S, Jenkinson M, Talbot K, Mackay CE, Hu M. 2014. Comprehensive morphometry of subcortical grey matter structures in early-stage Parkinson's disease. Hum Brain Mapp. 35:1681-1690.

Mogenson GJ, Jones DL, Yim CY. 1980. From motivation to action: functional interface between the limbic system and the motor system. Prog Neurobiol. 14:69-97.

Ng THB, Sowman PF, Brock J, Johnson BW. 2013. Neuromagnetic imaging reveals timing of volitional and anticipatory motor control in bimanual load lifting. Behav Brain Res. 247: 182-192.

O’Doherty J, Dayan P, Schultz J, Deichmann R, Friston K, Dolan RJ. 2004. Dissociable roles of ventral and dorsal striatum in instrumental conditioning. Science. 304:452-454.

Oldfield RC. 1971. The assessment and analysis of handedness: the Edinburgh inventory. Neuropsychologia. 9:97-113.

Patenaude B, Smith SM, Kennedy DN, Jenkinson M. 2011. A Bayesian model of shape and appearance for subcortical brain segmentation. NeuroImage. 56:907-922.

Pfefferbaum A, Mathalon DH, Sullivan EV, Rawles JM, Zipursky $\mathrm{RB}$, Lim KO. 1994. A quantitative magnetic resonance imaging study of changes in brain morphology from infancy to late adulthood. Arch Neurol. 51:874-887.
Posener JA, Wang L, Price JL, Gado MH, Province MA, Miller MI, Babb CM, Csernansky JG. 2003. High-dimensional mapping of the hippocampus in depression. Am J Psychiatry. 160:83-89.

Pruessner M, Pruessner JC, Hellhammer DH, Bruce Pike G, Lupien SJ. 2007. The associations among hippocampal volume, cortisol reactivity, and memory performance in healthy young men. Psychiatry Res. 155:1-10.

Puttemans V, Wenderoth N, Swinnen SP. 2005. Changes in brain activation during the acquisition of a multifrequency bimanual coordination task: from the cognitive stage to advanced levels of automaticity. J Neurosci. 25:4270-4278.

Qiu A, Crocetti D, Adler M, Mahone EM, Denckla MB, Miller MI, Mostofsky SH. 2009a. Basal ganglia volume and shape in children with attention deficit hyperactivity disorder. Am J Psychiatry. 166:74-82.

Qiu A, Taylor WD, Zhao Z, MacFall JR, Miller MI, Key CR, Payne ME, Steffens DC, Krishnan KRR. 2009b. APOE related hippocampal shape alteration in geriatric depression. NeuroImage. 44:620-626.

Qiu A, Younes L, Miller MI, Csernansky JG. 2008. Parallel transport in diffeomorphisms distinguishes the time-dependent pattern of hippocampal surface deformation due to healthy aging and the dementia of the Alzheimer's type. NeuroImage. 40:68-76.

Raz N, Lindenberger U, Rodrigue KM, Kennedy KM, Head D, Williamson A, Dahle C, Gerstorf D, Acker JD. 2005. Regional brain changes in aging healthy adults: general trends, individual differences and modifiers. Cereb Cortex. 15:1676-1689.

Raz N, Williamson A, Gunning-Dixon F, Head D, Acker JD. 2000. Neuroanatomical and cognitive correlates of adult age differences in acquisition of a perceptual-motor skill. Microsc Res Tech. 51:85-93.

Rémy F, Wenderoth N, Lipkens K, Swinnen SP. 2008. Acquisition of a new bimanual coordination pattern modulates the cerebral activations elicited by an intrinsic pattern: an fMRI study. Cortex. 44:482-493.

Resnick SM, Pham DL, Kraut MA, Zonderman AB, Davatzikos C. 2003. Longitudinal magnetic resonance imaging studies of older adults: a shrinking brain. J Neurosci. 23:3295-3301.

Rinaldi A, Oliverio A, Mele A. 2012. Spatial memory, plasticity and nucleus accumbens. Rev Neurosci. 23:527-541.

Rodrigue KM, Kennedy KM, Raz N. 2005. Aging and longitudinal change in perceptual-motor skill acquisition in healthy adults. J Gerontol B Psychol Sci Soc Sci. 60:P174-P181.

Roitman MF, Wheeler RA, Carelli RM. 2005. Nucleus accumbens neurons are innately tuned for rewarding and aversive taste stimuli, encode their predictors, and are linked to motor output. Neuron. 45:587-597.

Salat DH, Buckner RL, Snyder AZ, Greve DN, Desikan RSR, Busa E, Morris JC, Dale AM, Fischl B. 2004. Thinning of the cerebral cortex in aging. Cereb Cortex. 14:721-730.

Salmon DP, Butters N. 1995. Neurobiology of skill and habit learning. Curr Opin Neurobiol. 5:184-190.

Samanez-Larkin GR, Wagner AD, Knutson B. 2011. Expected value information improves financial risk taking across the adult life span. Soc Cogn Affect Neurosci. 6:207-217.

Sandman CA, Head K, Muftuler LT, Su L, Buss C, Davis EP. 2014. Shape of the basal ganglia in preadolescent children is associated with cognitive performance. NeuroImage. 99:93-102.

Schott BH, Niehaus L, Wittmann BC, Schütze H, Seidenbecher CI, Heinze H-J, Düzel E. 2007. Ageing and early-stage Parkinson's disease affect separable neural mechanisms of mesolimbic reward processing. Brain J Neurol. 130:2412-2424. 
Schuff N, Woerner N, Boreta L, Kornfield T, Shaw LM, Trojanowski JQ, Thompson PM, Jack CR, Weiner MW, Alzheimer's Disease Neuroimaging Initiative T. 2009. MRI of hippocampal volume loss in early Alzheimer's disease in relation to ApoE genotype and biomarkers. Brain. 132: 1067-1077.

Seidler RD, Bernard JA, Burutolu TB, Fling BW, Gordon MT, Gwin JT, Kwak Y, Lipps DB. 2010. Motor control and aging: links to age-related brain structural, functional, and biochemical effects. Neurosci Biobehav Rev. 34:721-733.

Serbruyns L, Leunissen I, Huysmans T, Cuypers K, Meesen RL, van Ruitenbeek P, Sijbers J, Swinnen SP. 2015. Subcortical volumetric changes across the adult lifespan: subregional thalamic atrophy accounts for age-related sensorimotor performance declines. Cortex. 65:128-138.

Simić G, Kostović I, Winblad B, Bogdanović N. 1997. Volume and number of neurons of the human hippocampal formation in normal aging and Alzheimer's disease. J Comp Neurol. 379: 482-494.

Sisti HM, Geurts M, Gooijers J, Heitger MH, Caeyenberghs K, Beets IAM, Serbruyns L, Leemans A, Swinnen SP. 2012. Microstructural organization of corpus callosum projections to prefrontal cortex predicts bimanual motor learning. Learn Mem. 19:351-357.

Sleimen-Malkoun R, Temprado J-J, Berton E. 2013. Age-related dedifferentiation of cognitive and motor slowing: insight from the comparison of Hick-Hyman and Fitts' laws. Front Aging Neurosci. 5:62.

Small SA, Nava AS, Perera GM, DeLaPaz R, Mayeux R, Stern Y. 2001. Circuit mechanisms underlying memory encoding and retrieval in the long axis of the hippocampal formation. Nat Neurosci. 4:442-449.

Smith CD, Walton A, Loveland AD, Umberger GH, Kryscio RJ, Gash DM. 2005. Memories that last in old age: motor skill learning and memory preservation. Neurobiol Aging. 26: 883-890.

Sowell ER, Delis D, Stiles J, Jernigan TL. 2001. Improved memory functioning and frontal lobe maturation between childhood and adolescence: a structural MRI study. J Int Neuropsychol Soc. 7:312-322.

Swinnen SP. 2002. Intermanual coordination: from behavioural principles to neural-network interactions. Nat Rev Neurosci. 3:348-359.

Swinnen SP, Verschueren SMP, Bogaerts H, Dounskaia N, Lee TD, Stelmach GE, Serrien DJ. 1998. Age-related deficits in motor learning and differences in feedback processing during the production of a bimanual coordination pattern. Cogn Neuropsychol. 15:439-466.

Swinnen SP, Wenderoth N. 2004. Two hands, one brain: cognitive neuroscience of bimanual skill. Trends Cogn Sci. 8:18-25.

Tomassini V, Jbabdi S, Kincses ZT, Bosnell R, Douaud G, Pozzilli C, Matthews PM, Johansen-Berg H. 2011. Structural and functional bases for individual differences in motor learning. Hum Brain Mapp. 32:494-508.

Toni I, Krams M, Turner R, Passingham RE. 1998. The time course of changes during motor sequence learning: a wholebrain fMRI study. NeuroImage. 8:50-61.

Tubau E, Escera C, Carral V, Corral M-J. 2007. Individual differences in sequence learning and auditory pattern sensitivity as revealed with evoked potentials. Eur J Neurosci. 26:261-264.

Tziortzi AC, Haber SN, Searle GE, Tsoumpas C, Long CJ, Shotbolt P, Douaud G, Jbabdi S, Behrens TEJ, Rabiner EA, et al. 2014. Connectivity-based functional analysis of dopamine release in the striatum using diffusion-weighted MRI and positron emission tomography. Cereb Cortex. 24:1165-1177.

Unsworth N, Engle RW. 2005. Individual differences in working memory capacity and learning: evidence from the serial reaction time task. Mem Cognit. 33:213-220.

Vaillancourt DE, Spraker MB, Prodoehl J, Zhou XJ, Little DM. 2012. Effects of aging on the ventral and dorsal substantia nigra using diffusion tensor imaging. Neurobiol Aging. 33:35-42.

Van Petten C. 2004. Relationship between hippocampal volume and memory ability in healthy individuals across the lifespan: review and meta-analysis. Neuropsychologia. 42:1394-1413.

Videbech P, Ravnkilde B. 2004. Hippocampal volume and depression: a meta-analysis of MRI studies. Am J Psychiatry. 161:1957-1966.

Voelcker-Rehage C. 2008. Motor-skill learning in older adults-a review of studies on age-related differences. Eur Rev Aging Phys Act. 5:5-16.

Volkow ND, Gur RC, Wang GJ, Fowler JS, Moberg PJ, Ding YS, Hitzemann R, Smith G, Logan J. 1998. Association between decline in brain dopamine activity with age and cognitive and motor impairment in healthy individuals. Am J Psychiatry. 155:344-349.

Walhovd KB, Fjell AM, Reinvang I, Lundervold A, Dale AM, Eilertsen DE, Quinn BT, Salat D, Makris N, Fischl B. 2005. Effects of age on volumes of cortex, white matter and subcortical structures. Neurobiol Aging. 26:1261-1270.

Wenderoth N, Toni I, Bedeleem S, Debaere F, Swinnen SP. 2006. Information processing in human parieto-frontal circuits during goal-directed bimanual movements. NeuroImage. 31: 264-278.

Wishart LR, Lee TD, Murdoch JE, Hodges NJ. 2000. Effects of aging on automatic and effortful processes in bimanual coordination. J Gerontol B Psychol Sci Soc Sci. 55:P85-P94.

Wu T, Wang L, Hallett M, Li K, Chan P. 2010. Neural correlates of bimanual anti-phase and in-phase movements in Parkinson's disease. Brain J Neurol. 133:2394-2409.

Zarei M, Patenaude B, Damoiseaux J, Morgese C, Smith S, Matthews PM, Barkhof F, Rombouts S, Sanz-Arigita E, Jenkinson M. 2010. Combining shape and connectivity analysis: an MRI study of thalamic degeneration in Alzheimer's disease. NeuroImage. 49:1-8. 